\title{
Article \\ Impact of Hydraulic System Stiffness on Its Energy Losses and Its Efficiency in Positioning Mechanical Systems
}

\author{
Piotr Dudziński * and Aleksander Skurjat (D)
}

Citation: Dudziński, P.; Skurjat, A. Impact of Hydraulic System Stiffness on Its Energy Losses and Its Efficiency in Positioning Mechanical Systems. Energies 2022, 15, 294. https:// doi.org/10.3390/en15010294

Academic Editor: Stefano Ubertini

Received: 30 November 2021

Accepted: 21 December 2021

Published: 1 January 2022

Publisher's Note: MDPI stays neutral with regard to jurisdictional claims in published maps and institutional affiliations.

Copyright: (c) 2022 by the authors. Licensee MDPI, Basel, Switzerland. This article is an open access article distributed under the terms and conditions of the Creative Commons Attribution (CC BY) license (https:/ / creativecommons.org/licenses/by/ $4.0 /)$.

\author{
Department of Off-Road Machine and Vehicle Engineering, Faculty of Mechanical Engineering, \\ Wroclaw University of Science and Technology, Wybrzeże Wyspiańskiego 27, 50-370 Wroclaw, Poland; \\ aleksander.skurjat@pwr.edu.pl \\ * Correspondence: piotr.dudzinski@pwr.edu.pl
}

\begin{abstract}
Hydraulic steering systems for mechanical devices, for example, manipulators or vehicle steering systems, should be able to achieve high positioning precision with high energy efficiency. However, this condition is very often not met in practical applications. This is usually due to the stiffness of the hydraulic system being too low. As a result, additional corrections are required to achieve the required positioning precision. Unfortunately, this means additional energy losses in the hydraulic control system. In this study, this problem is presented using the example of a hydraulic steering system for an articulated frame steer vehicle. This hydraulic steering system should provide the required directional stability for road traffic safety reasons. So far, this issue, connected mainly with the harmful phenomenon of so-called vehicle snaking behaviour, has not been solved sufficiently practically. To meet the needs of industrial practice, taking into account the current global state of knowledge and technology, Wrocław University of Science and Technology is performing comprehensive experimental and computational studies on the snaking behaviour of an articulated frame steer wheeled commercial vehicle. The results of these tests and analyses showed that the main cause of problems that lead to the snaking behaviour of this vehicle class is the effective torsional stiffness of the hydraulic steering system. For this reason, a novel mathematical model of the effective torsional stiffness was developed and validated. This model comprehensively took into account all important mechanical and hydraulic factors that affect the stiffness of a hydraulic system, resulting in the examined snaking behaviour. Because of this, it is possible at the design stage to select the optimal parameters of the hydraulic steering system to minimise any adverse influence on the snaking behaviour of articulated frame steer wheeled vehicles. This leads to minimising the number of required corrections and minimising energy losses in this hydraulic steering system. The innovative model presented in the article can be used to optimise positioning accuracy, for example, in manipulators and any mechanical system with hydraulic steering of any system of any mechanical parts.
\end{abstract}

Keywords: hydraulic system stiffness; minimising energy losses; efficiency in positioning; articulated frame wheeled vehicles; snaking

\section{Introduction}

In the development of wheeled vehicles for applications mainly in construction, mining, agriculture, forestry, etc., the breakthrough factor was the introduction of articulated frame steer wheeled vehicles (AFSWVs). Vehicles with such applications are defined in the literature as commercial vehicles. In AFSWVs, in contrast to conventional vehicles with the so-called Ackerman steering system or vehicles with steering axles, the wheels are fixed to the frame for straight-ahead driving, i.e., they are not steerable. On the other hand, the suspension of the selected wheels can be of any design, i.e., dependent, independent, with or without additional spring elements. In practice, the dependent suspensions are very often used as one of the oscillating axles (OJ, Figure 1) or one of the oscillating frames [1]. 
The AFSWV usually consists of two members (frames) with large masses connected by a steering joint. In the state of the art, vehicles with three or more members are also known [1]. An AFSWV is steered as a result of mutual steering of members (frames) relative to each other that are forced usually by means of a hydraulic steering mechanism. This hydraulic steering mechanism fulfils a double role in an AFSWV. It should provide the vehicle with the required steerability (manoeuvrability) (Figure 1) and, at the same time, guarantee the necessary directional stability when travelling at high speeds by keeping the same position of steering system pistons. The main advantage of AFSWVs is their high manoeuvrability with a relatively simple solution for the undercarriage as shown in Figure $1 \mathrm{a}-\mathrm{f}$ while comparing outer and inner turning radius for different steering systems.

a) Front-wheel steering

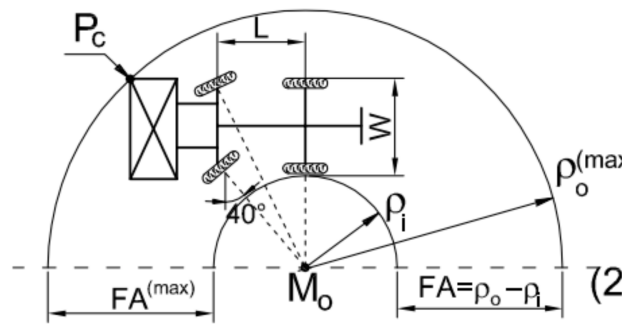

b) Rear-wheel steering

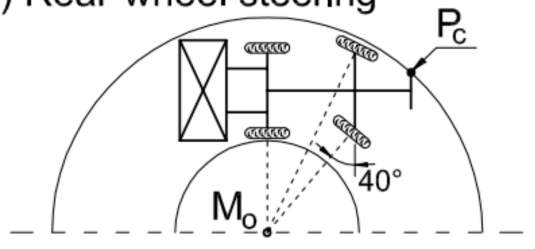

c) Four-wheel steering

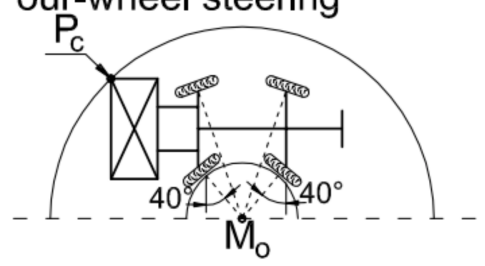

d) Articulated-frame steering

(2)

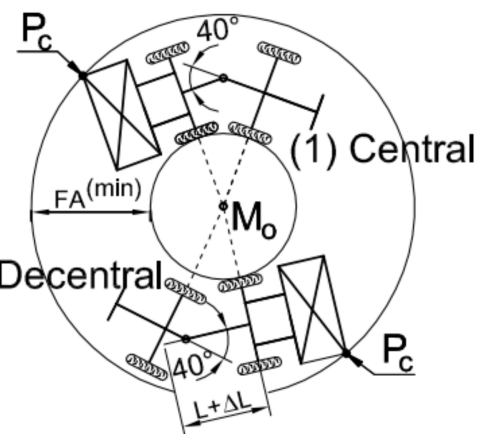

e) One-axle steering

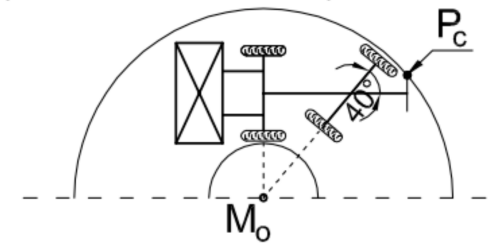

f) Combined steering

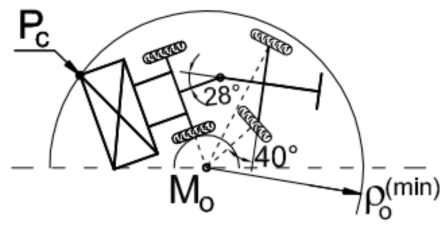

Figure 1. Comparison of the manoeuvrability of wheeled loaders with different undercarriage configurations in terms of steering systems [1].

In contrast, in vehicles with the Ackerman steering system, the steering mechanisms have a complex multi-joint lever structure. In addition, there are wear-sensitive constant velocity $(\mathrm{CV})$ joints in the driven steering wheels. Consequently, these systems, primarily due to their structure and high dynamic operating loads, are more prone to failure.

One of the current trends in AFSWVs is the increase in their ability to travel at speeds of $50-60 \mathrm{~km} / \mathrm{h}$ or even $100 \mathrm{~km} / \mathrm{h}$. An example of this can be found in military engineering machines [2]. These new requirements have revealed several previously unknown dynamics problems in this class of vehicles. One of the negative phenomena is the so-called vehicle snaking behaviour. The term snaking behaviour should be understood as a regular increase in the deviation of the vehicle from the assumed direction (path) of travel, which requires corrections by the driver (Figure 2). As a result, the resulting path of travel has an oscillatory character. The amplitude of these oscillations increases with increasing driving speed and causes the discrepancy between the assumed and actual trajectory, which is characterised by the side-slip angle of the vehicle $\beta$ (Figure 2). The obtained amplitude $A_{f}$ is a result of mainly the angle of articulation angle AJ, vehicle velocity, frames of inertia, and masses. 


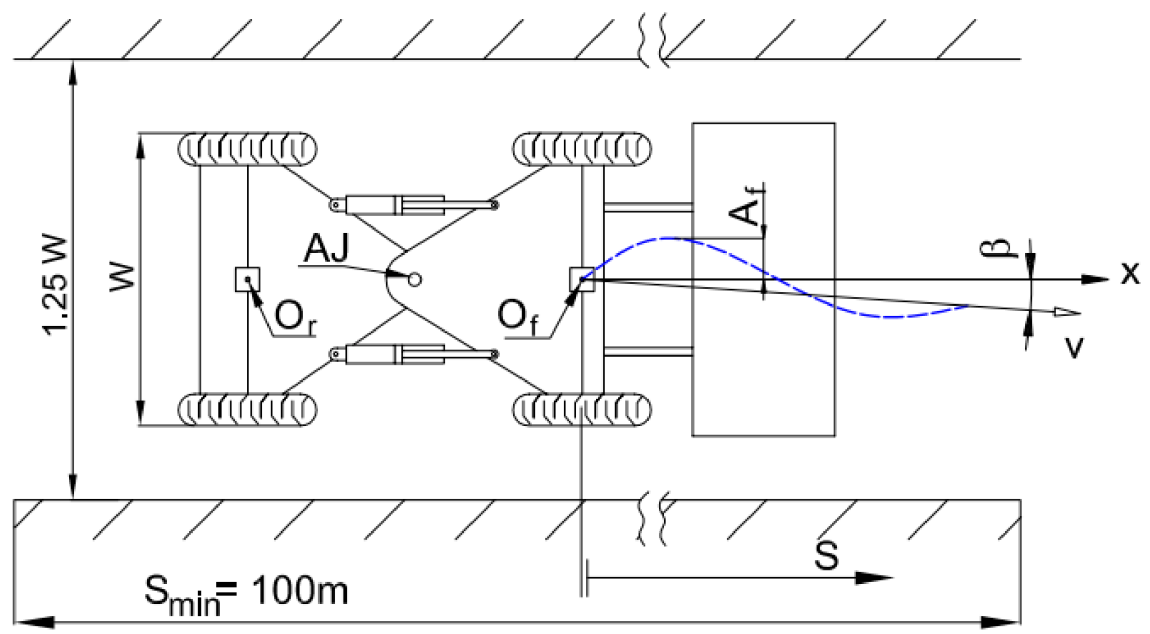

Figure 2. Requirements concerning the steering system of an ASFWV (commercial vehicle), specified in standards [3-6].

Taking the geometric centre of the front axle $\mathrm{O}_{\mathrm{f}}$ (Figure 2) as a representative point for the analysis, the basic indicators of directional stability and the associated snaking of the articulated vehicle are the amplitude $A_{f}$ of the horizontal deflection of the centre of the axle $\mathrm{O}_{\mathrm{f}}$ and the frequency $1 / \mathrm{T}_{\mathrm{f}}$ of its occurrence. This problem is so important that for safety reasons, appropriate standards were prepared [3-6]. According to these requirements, the steering system should provide a possibility of rectilinear forward travel of the AFSWV, with a maximum speed of $\mathrm{v}_{\max }$, on a road section with a horizontal, even, hard, and dry road surface, with a length of at least $S_{\min }=100 \mathrm{~m}$ and a width equal to 1.25 times the value of the contour track of the undercarriage running wheels W (Figure 2).

Typical driver adjustments using the steering mechanism are allowed in the road section. Simultaneously, according to [3-6], "loosing" the steering wheel or control lever should not cause deviations from the rectilinear vehicle travel related to exceeding the limits of the standard track $1.25 \mathrm{~W}$ in a section not shorter than $20 \mathrm{~m}$. Driving AFSWVs on public roads places additional higher requirements on them. The observations and tests indicate that the snaking frequency is about $1 \mathrm{~Hz}$ and the amplitude $\mathrm{A}_{\mathrm{f}}$ increases with velocity and decreases with the stiffness of the steering system. For this reason, to keep the vehicle in the road lane, a driver uses the steering system to correct the path and wastes energy.

Meeting the needs of the market, the Department of Off-Road Machine and Vehicle Engineering of Wrocław University of Science and Technology in Poland has carried out systematic work for many years in the field of simulation and experimental research and in the field of creating innovative solutions for AFSWVs, including the issue of their snaking behaviour.

Research showed that a significant cause of AFSWV snaking behaviour is the elasticdamping parameters of the hydrostatic steering mechanism. It should be added that, in practice, with too low effective (equivalent) stiffness of the AFSWV steering system, the so-called jack-knife phenomenon may occur. In such a case, the AFSWV members (frames) rotate in relation to each other by a certain angle of articulation $\gamma$ and during travel under constant conditions, the vehicle maintains this angle at approximately the same level.

In this manuscript, an original, mathematical model of the effective (equivalent) torsional stiffness of a hydrostatic steering system AFSWV with two hydraulic actuators is presented. This experimentally verified model allows engineers, at the design stage, to optimally select the parameters of the steering system in terms of increasing steering system stiffness and minimising snaking behaviour, and saving energy by limiting the number of required vehicle path corrections. The model can also be applied to any mechanical 
system with a hydraulic steering system, for example, machine manipulators that need to ensure the accuracy of their manipulator positioning.

\section{Snaking Behaviour of an Articulated Frame Steer Wheeled Vehicle-State of the Art}

In the literature, there is a series of monographs and publications concerning the directional stability of classic motor vehicles, e.g., [7,8]. Unfortunately, the results of these works cannot be transferred directly into considerations regarding commercial AFSWVs because the latter differ significantly from motor vehicles using a conventional steering system for wheels since they use a so-called Ackermann steering geometry.

In addition to the steering system, the significant differences between automotive vehicles and commercial AFSWVs are dominated primarily by the elastic-damping properties of the hydraulic steering mechanism and the dynamic properties of the large-sized so-called inertial tyres of commercial vehicles and their interaction with a variety of ground types [1]. The commonly used hydraulic steering system must, apart from providing the vehicle with the required steerability, guarantee the necessary directional stability and safety of driving at high speeds on public roads.

The movement of AFSWVs takes place under complicated operational conditions connected with numerous factors affecting the correctness of the movement strategy chosen by the machine operator (Figure 3).
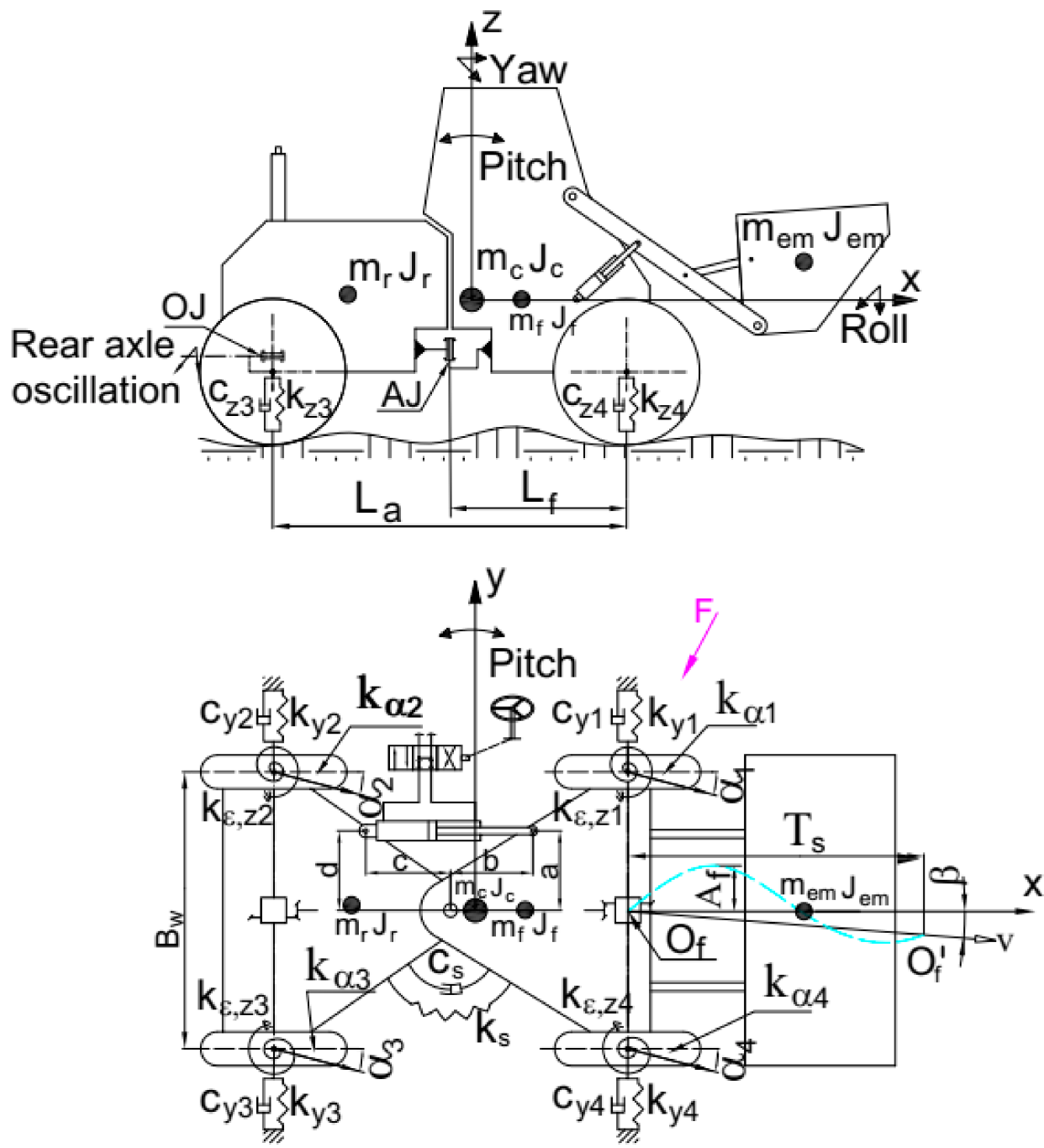

Figure 3. Main factors influencing the directional stability of an articulated frame steer wheeled vehicle/machine. 
The authors' studies of AFSWVs $[1,9,10]$ showed that some of the factors change according to the driver's intention (e.g., direction and speed of the vehicle's movement v); front-, rear-, or all-wheel drive; and driving or braking force. On the other hand, a large group of factors is defined already in the early design stage of this vehicle class: these are connected with the assumed design parameters of the vehicle itself, which affect, among others, the angular oscillations $\pm \Delta \gamma$ of its member (frames) in the articulation joint $\mathrm{AJ}$, the actual movement trajectory, and the number of the operator's corrections necessary to maintain the vehicle on its desired course.

The most important parameters of this set include the mass distribution $\mathrm{m}_{\mathrm{f}}, \mathrm{m}_{\mathrm{r}}$, and $\mathrm{m}_{\mathrm{em}}$ and moments of inertia $\mathrm{J}_{\mathrm{f}}, \mathrm{J}_{\mathrm{r}}$, and $\mathrm{J}_{\mathrm{em}}$ of the main AFSWV members (frames); axle base $L_{a}$; wheel base $B_{w}$; design solution and positioning $L_{f} / L_{a}$ of the articulation joint $\mathrm{AJ}$ and oscillation joint OJ of the AFSWV; and elastic-damping properties $\mathrm{k}_{\mathrm{z}, \mathrm{i}}, \mathrm{k}_{\mathrm{y}, \mathrm{i}}$, $\mathrm{k}_{\alpha, \mathrm{i}}, \mathrm{k}_{\varepsilon z, \mathrm{i}}, \mathrm{c}_{\mathrm{z}, \mathrm{i}}$, and $\mathrm{c}_{\mathrm{y}, \mathrm{i}}$ of large-size tyres. It should be emphasised that a very significant role in the AFSWV's snaking behaviour is played by geometry, the design solution of the steering system, and its elastic-damping properties $\left(\mathrm{k}_{\mathrm{s}}, \mathrm{c}_{\mathrm{s}}\right)$ connected with this, as well as the so-called amplification factor of the steering system. The amplification factor of the steering system $\lambda_{\mathrm{S}}=1 / \mathrm{n}$ is defined as the inverse of the number of revolutions $\mathrm{n}$ of the steering wheel performed to cover the full steering range of the vehicle, i.e., from its right extreme position to the left extreme position [11]. For example, according to the recommendations of the AFSWV manufacturers [12], the number of revolutions $n$ of the steering wheel performed to cover the full steering range of the vehicle is constant and its value depends on the class of vehicle but is most often selected in the range of 3.5-6. Field tests carried out by the authors indicate that the amplification factor $\lambda_{\mathrm{s}}$ of a steering system should have an adaptively variable value that is adequate for the required operational conditions. For example, when loading a wheel loader onto a transport vehicle, the amplification factor of the steering system should be in the range of $1 \leq \lambda_{\mathrm{s}} \leq 0.5$ $(1 \leq \mathrm{n} \leq 2)$, but while driving this vehicle on public roads, to ensure precise and safe correction of travel direction, an amplification factor $\lambda_{\mathrm{s}}$ value from the range of $1 / 4 \leq \lambda_{\mathrm{s}} \leq 1 / 6$ $(4 \leq \mathrm{n} \leq 6)$ is recommended. A solution for such a novel system was presented by the authors in papers $[11,13]$.

Other factors include surface roughness and inclination, movement resistances, influence of wind-generated oscillations, the so-called galloping (pitch), oscillations around the longitudinal vehicle axis $\mathrm{x}$ (roll), oscillations around the vertical vehicle axis $\mathrm{z}$ (yaw), and oscillations of one of the members in the steering joint (OJ). As a rule, these factors have the characteristics of random disturbances of the vehicle's directional stability.

The significant factors affecting the AFSWVs listed above, while also taking into account the vehicle's design parameters and the driver's competence and psychophysical predisposition, cause a discrepancy between the assumed and the actual movement trajectory, defined as the side-slip angle of the vehicle $\beta$ (Figure 3).

The published literature lacks extensive and comprehensive studies on the significant problem of AFSWV's snaking behaviour. Known interesting papers usually solve some selected problems but they do not comprehensively take into account all the important factors from this broad field.

The structural flexibility of a steel actuator and the compressibility of the fluid are discussed in paper [14]. The authors indicate that the position of the piston, the bulk modulus of the fluid, and the Young modulus of the steel tube affect the total stiffness of a cylinder.

The stiffness model of a hydraulic cylinder, including the bulk modulus of oil, the air content, the axial deformation of the piston rod, the expansion of a cylinder barrel, the expansion of flexible hoses, and the deformation of the sealing of actuators, was established in [15]. A mathematical model for the stiffness calculation was proposed. However, this model requires some coefficient that is not shown to predict the total stiffness value. The authors indicated that oil pressure below $6 \mathrm{MPa}$ and air content play an important role. 
In paper [16], a knee load exoskeleton with a stiffness of the hydraulic actuator and mechanical structure is discussed.

The first publications in the field of AFSWV's snaking behaviour [17] include a mathematical model of an AFSWV with three degrees of freedom, with which the authors presented a steering hydraulic system as an equivalent torsion spring with dampening. In this model, some important parameters affecting the stiffness of this mechanism were omitted, namely, nonlinear elasticity parameters of hydraulic hoses and nonlinear dependence between modulus of elasticity of the liquid and its gas content. In addition, the influence of wheel contact with the surface on values of this global stiffness and dampening was not taken into account. In this paper, as well as in other subsequent publications [18-22], it was shown that the main causes of the AFSWV's snaking behaviour are low stiffness and dampening of the steering system; mass distribution and inertia of the members of the vehicle; dynamic properties of the vehicle's tyres; front-, rear-, or all-wheel drive; and the speed of the vehicle. In earlier papers $[1,23,24]$, the problem of the snaking behaviour of AFSWVs was considered in relatively high detail. It was ascertained that the value of equivalent stiffness of the steering system is affected by, first of all, the elasticity of the working fluid, its air content, the elasticity of the walls of flexible hydraulic hoses, and geometrical parameters of the hydrostatic steering mechanism. It was determined that leaks of the separator of the working fluid in the steering system's directional valve affect the damping value. The so-called inertial nature of operation of large-size tyres in comparison to motor vehicle tyres was brought to attention. Furthermore, it was proven that significant parameters that affect the snaking behaviour of AFSWVs are the positioning of the centre of the gravity, location of the articulation joint and rotation joint of the rear swing axle, and the speed of the vehicle. It was shown that front- and all-wheel drive without a differential mechanism between axes reduces the AFSWV snaking phenomenon. On the other hand, studies of $[2,25]$, which were carried out using four different designs of an AFSWV's steering system, indicated the occurrence of an accumulated residual moment, which, after a decrease in the vehicle's steering resistance, causes an automatic change in the piston stroke of hydraulic actuators. This phenomenon leads to an undesirable change in the steering angle of the vehicle's members, which may be a cause for snaking behaviour. In the experiments shown in these articles, other factors that were observed to affect the snaking behaviour of the AFSWV travel include delays of the steering system itself, the amplification value of the hydraulic valves of the steering system, the kinematics of the steering system, and the experience of the operator. Furthermore, the influence of the lateral stiffness of the tyres on the vehicle's trajectory was investigated. It was shown that when the tyre inflation pressure increases, the oscillation amplitude obtained during the determination of the trajectory exhibits a tendency to decrease in relation to the rectilinear course expected by the driver.

The effects of the characteristics of the front and rear tyres on the snaking behaviour of articulated steer vehicles are presented in [18]. The author indicates that the locking axle differential mechanism can affect the trajectory of a vehicle. The stiffness of the articulation steering system is calculated.

The hydraulic force control system created by adding hydraulic compliance is proposed in [26]. The inclusion of more capacitive components allows for a reduction in the effective bulk modulus and lowers the total mechanical stiffness. The authors presented the possibility of improving the stability performance and disturbance rejection of the force control system.

\section{Experimental Tests of Effective Torsional Stiffness for the Hydraulic Steering System}

To identify the torsional stiffness of the AFSWV torsion system, experimental tests were carried out on a Ł220 loader (Figure 4). 


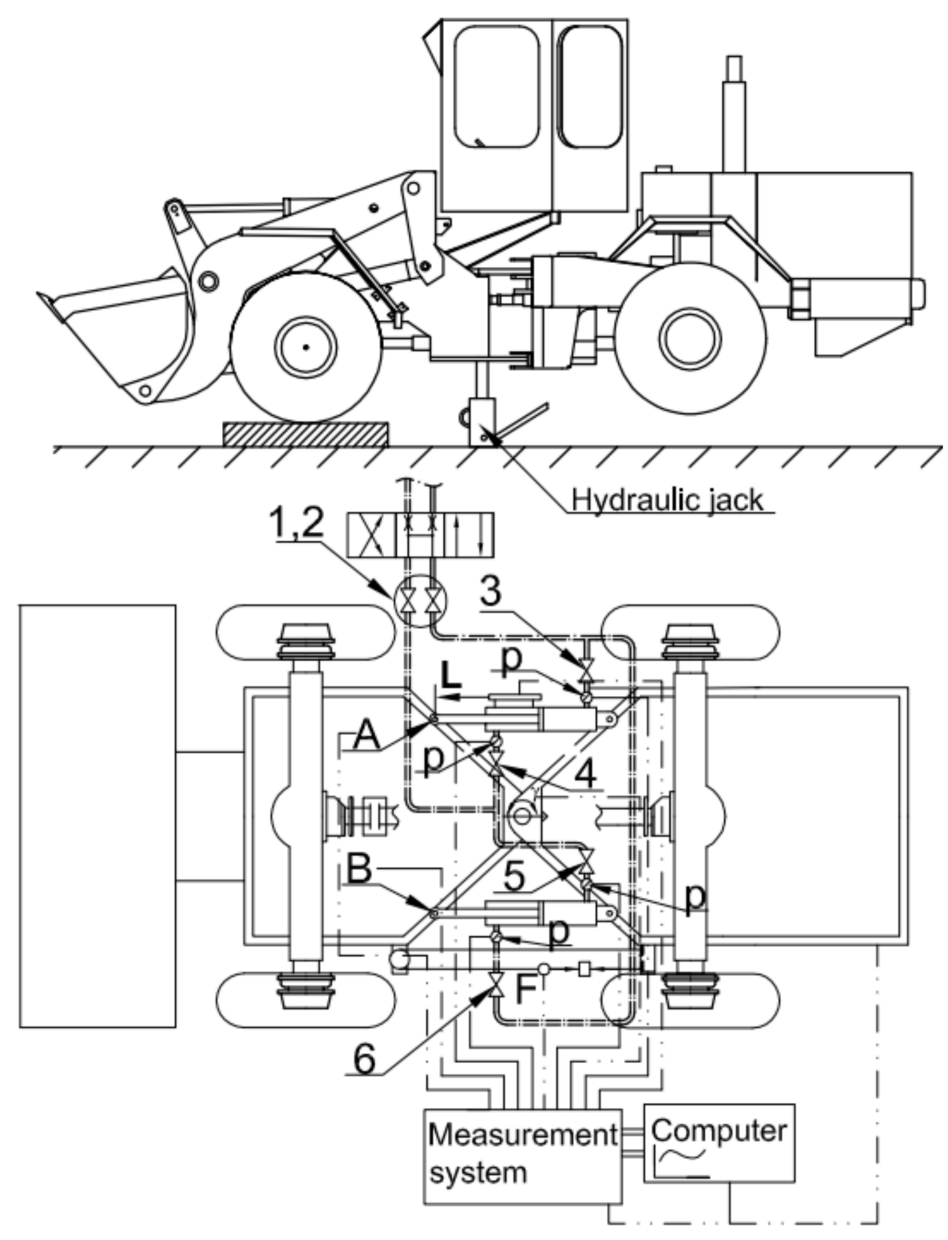

Figure 4. Articulated frame steer test machine (wheel loader Ł220) equipped with a measurement system for the identification of torsional stiffness of a steering mechanism: 1,2-cut-off valves installed at the outlet and the inlet of a hydraulic line of the steering system; 3,4,5,6-cut-off valves installed at the outlet and the inlet of the steering hydraulic actuator; 7-angle sensor for measurement of articulation angle $\Delta \gamma ; p$-sensors to measure chambers pressure of the steering cylinders; $\mathrm{L}$-transducer for measurement of the piston rod displacement of the steering actuator; $\mathrm{A}, \mathrm{B}$ - force measurement in the hydraulic actuator pin; $\mathrm{F}$-the device generating the steering torque $\Delta \mathrm{M}_{\mathrm{S}}$ for the machine members (frames) in the steering joint.

During the tests, the steering system wheel was locked and the machine members (frames) in the articulated joint were rotated due to $\mathrm{AJ}$ joint at vehicle standstill by using an external force device between the vehicle's frames. Torsional stiffness tests of the hydraulic steering system were performed with proper use of cut-off valves 1, 2, 3, 4, 5, and 6 to measure the influence of flexible hydraulic hoses (Figure 4, compression of the fluid and wall expandicity). The tests were carried out with the rear axle of the machine raised (test mode 1). To identify the influence of the tyres on the effective torsional stiffness in the steering joint, tests were carried out analogically only for the machine standing with all wheels on concrete (test mode 2). Test results are presented in Figure 5.

The experimental results showed a very significant influence of flexible hydraulic hoses used in the steering system on effective torsional stiffness $k_{s}$ in the articulated joint. It should be noted that the parameters of the large-sized tyres of the tested machine also affected the effective stiffness in the articulated joint. 


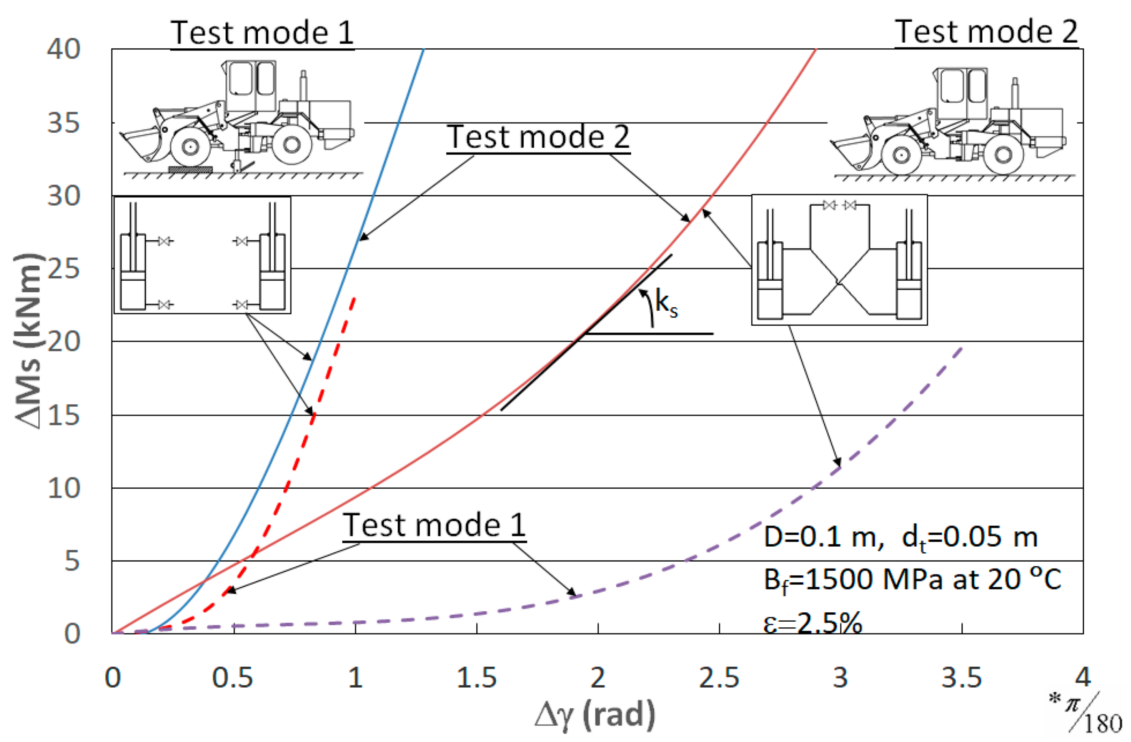

Figure 5. Test results of the effective torsional stiffness $\mathrm{k}_{\mathrm{s}}=\partial \mathrm{Ms} / \partial \gamma$ of the hydraulic steering mechanism of the test machine (wheel loader $Ł 220$ ); $\Delta \mathrm{M}_{S}$-steering torque around the articulation joint; $\Delta \gamma$-articulation angle.

In the literature and materials of companies producing flexible hydraulic hoses, there is no comprehensive information on their elastic properties, especially the wall expandicity. Some information on this subject can be found in works $[24,27,28]$. To identify the influence of the flexible hydraulic hoses used in hydraulic systems, the Department of Off-Road Machine and Vehicle Engineering carried out experimental research in a laboratory station (Figure 6).

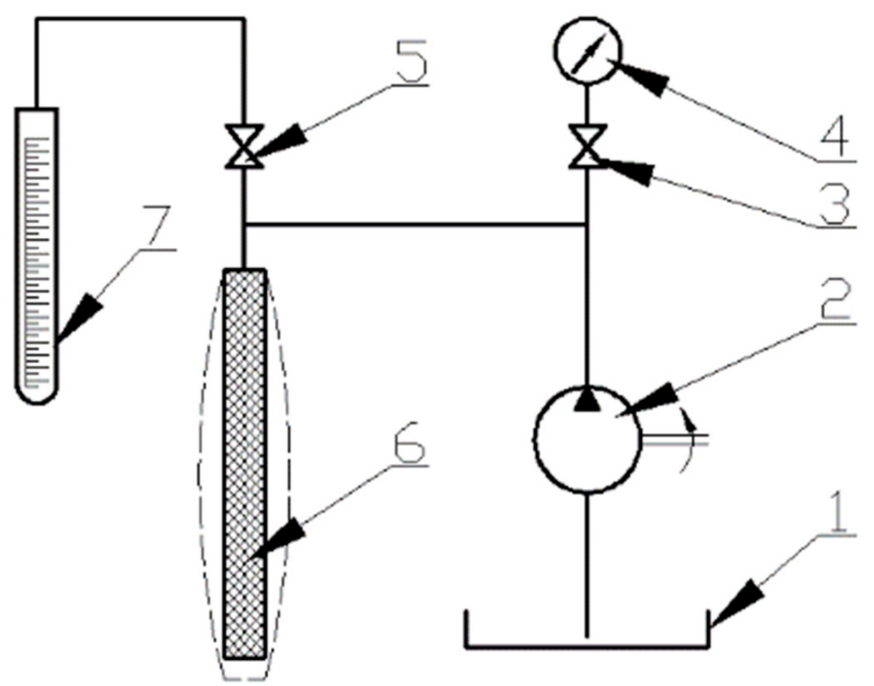

Figure 6. Schematic diagram of a laboratory stand for hydraulic hoses internal volume expansion: 1-tank; 2-manual pump; 3,5-cut-off valves; 4-pressure sensor $\Delta \mathrm{p}_{\mathrm{i}}$ of the fluid; 6-tested hydraulic hose; $7-$ measurement vessel.

The tests were carried out for the following pressures $\Delta \mathrm{p}_{\mathrm{i}}$ in the hoses: $2.5,5,7.5,10$, 12.5 , and $16 \mathrm{MPa}$ at $20^{\circ} \mathrm{C}$ using hydraulic oil. The measurement was commenced after filling a hydraulic hose with the fluid having a volume of $\mathrm{V}_{0}$ and removing the air in the form of possibly included bubbles. The fluid outflow from manual pump 2 was cut off with valve 5. Then, generating the flow using 2 resulted in a pressure increase to value $\Delta \mathrm{p}_{\mathrm{i}}$, leading to a deformation of the tested hose; then, valve 3 was closed. When valve 5 was 
opened, a fluid volume $\Delta \mathrm{V}_{\mathrm{zm}}$ was liberated to the measurement vessel 7 that was a sum of the volume $\Delta \mathrm{V}_{\mathrm{p}}$ resulting from the hydraulic hose wall expandicity and the volume resulting from the fluid's compressibility $\Delta \mathrm{V}_{\mathrm{c}}$, namely,

$$
\Delta \mathrm{V}_{\mathrm{zm}}=\Delta \mathrm{V}_{\mathrm{p}}+\left|-\Delta \mathrm{V}_{\mathrm{c}}\right|
$$

where

$$
\Delta \mathrm{V}_{\mathrm{c}}=-\frac{\mathrm{V}_{0, \mathrm{p}} \Delta \mathrm{p}_{\mathrm{i}}}{\mathrm{B}_{\mathrm{f}}}
$$

To make the tests of elastic properties of hydraulic hoses independent from the compressibility of the fluid applied, similar tests were carried out on a laboratory stand using a thick-walled steel pipe instead of the flexible hydraulic hose. In this case, the following dependence was valid: $\Delta \mathrm{V}_{\mathrm{zm}}=\Delta \mathrm{V}_{\mathrm{f}}$. Example test results are shown in Figure 7 .

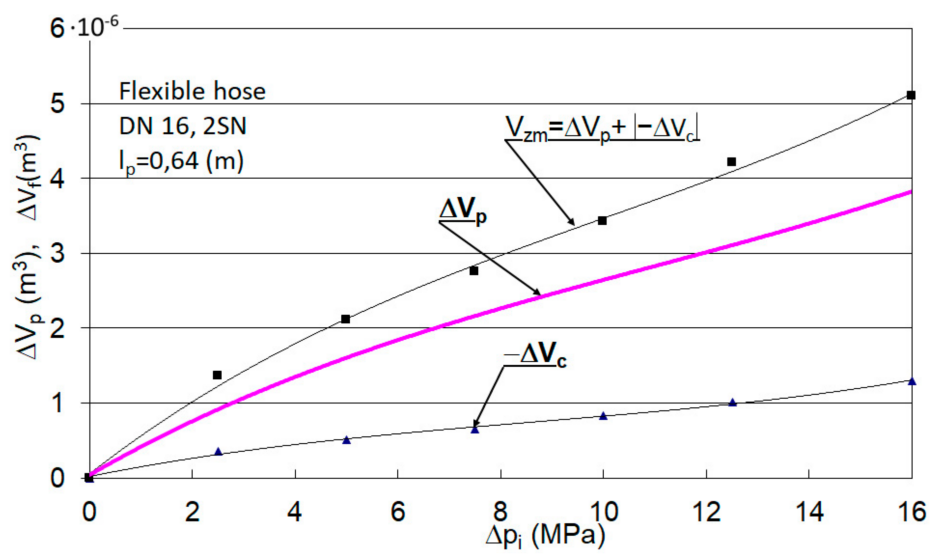

Figure 7. Test results for changes in the hose internal volume $\Delta V_{p}$ and changes in the fluid volume $\Delta \mathrm{V}_{\mathrm{f}}$ vs. internal pressure $\Delta \mathrm{p}_{\mathrm{i}}$ in the hose.

For the purpose of quantitative comparative analysis of the elastic properties of various hydraulic hoses, a volume expansion factor $\lambda_{p}$ was introduced, which was defined as:

$$
\lambda_{\mathrm{p}}=\frac{\Delta \mathrm{V}_{\mathrm{p}}}{\mathrm{V}_{0, \mathrm{p}}}
$$

Selected results of experimental tests, taking into account relevant constructional as well as operational parameters of typical flexible hydraulic lines used in the steering systems of industrial vehicles, are presented in Figure 8. More results are published in [24].

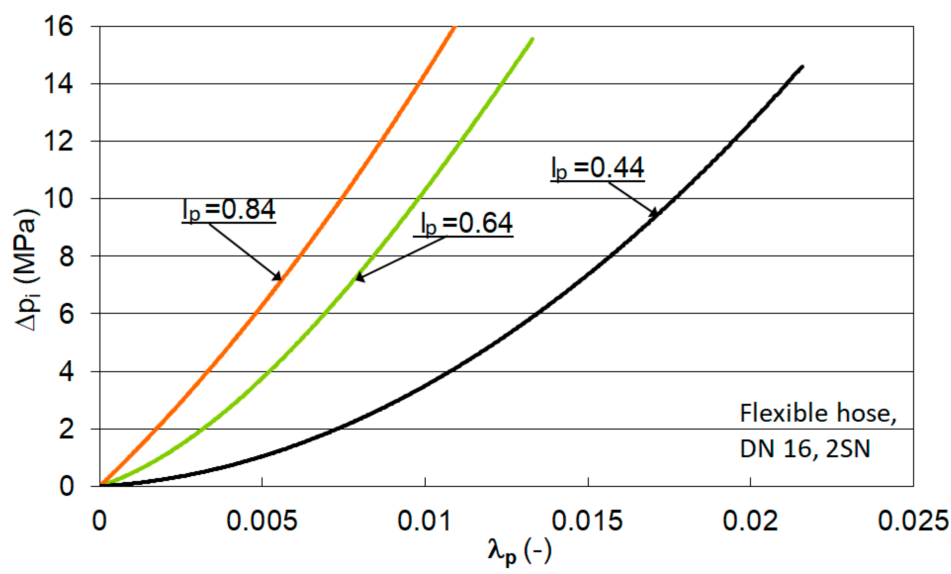

Figure 8. Influence of internal pressure $\Delta \mathrm{p}_{\mathrm{i}}$ on volume expansion coefficient $\lambda_{\mathrm{p}}$ of hoses with a nominal diameter of $16 \mathrm{~mm}$ (DN16) and two carcass layers (2SN) vs. their length $\mathrm{l}_{\mathrm{p}}$ [24]. 
Depending on the requirements, the experimental results enabled the determination of the bulk modulus of hoses $B_{p}$ according to the adopted definitions [29], namely,

- $\quad$ tangent bulk modulus $\mathrm{B}_{\mathrm{p}}$ of the hose:

$$
\mathrm{B}_{\mathrm{p}}=\frac{\partial \mathrm{p}_{\mathrm{i}}}{\partial \lambda_{\mathrm{p}}}
$$

or

- $\quad$ secant bulk modulus $\overline{\mathrm{B}_{\mathrm{p}}}$ of the hose:

$$
\overline{\mathrm{B}_{\mathrm{p}}}=\frac{\Delta \mathrm{p}_{\mathrm{w}}}{\Delta \lambda_{\mathrm{p}}}
$$

Based on Equation (4) for the hydraulic hoses used in the test machine (Figure 6), their bulk modulus values were determined as shown in Figure 9.

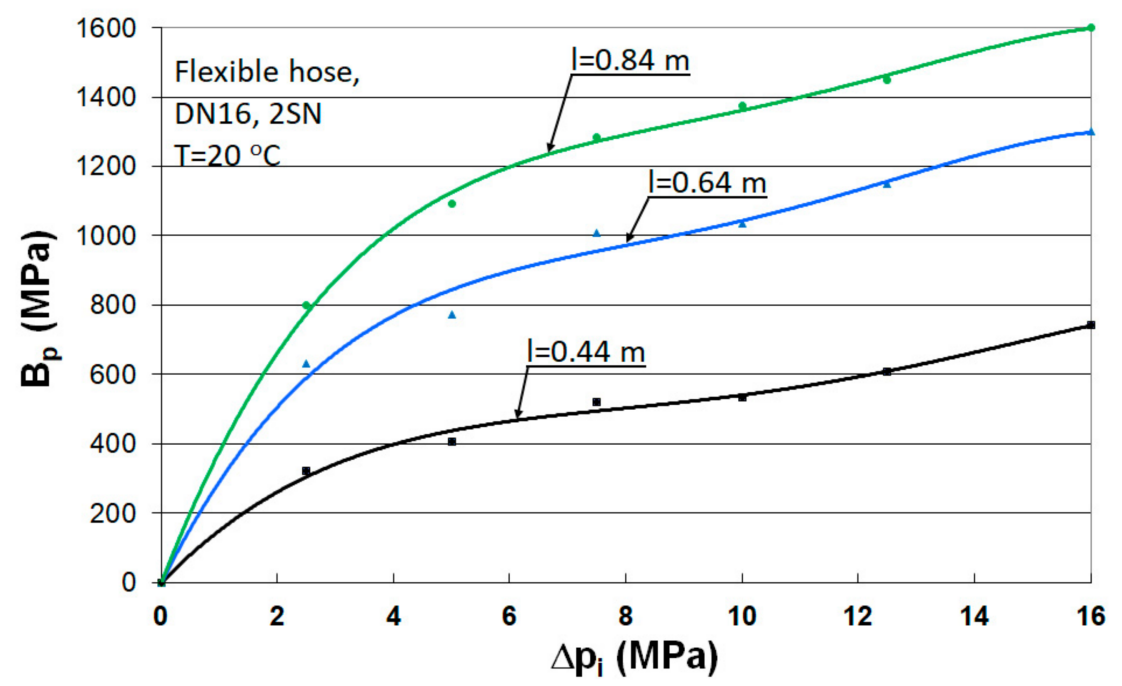

Figure 9. Dependence of the bulk modulus $B_{p}$ of hydraulic hoses $2 \mathrm{SN}$, with $d=16 \mathrm{~mm}$ used in the steering mechanism of the test machine vs. internal pressure $\Delta \mathrm{p}_{\mathrm{i}}$ for various hose lengths $\mathrm{l}_{\mathrm{p}}$.

The research by the authors of this paper and [27] showed that for the flexible hoses with typical installation bends and with an increase in the hydraulic oil temperature during operation from $20^{\circ} \mathrm{C}$ to approx. $60^{\circ} \mathrm{C}$, the bulk modulus $\mathrm{B}_{\mathrm{p}}$ of these hoses, which were obtained in the laboratory tests presented above, should be reduced by approx. $15 \%$. Thus, the effective bulk modulus $B_{p, e}$ of these hoses will be assumed as $B_{p, e}=0.85 B_{p}$ in further considerations.

Hydraulic oil maintained under atmospheric pressure for a prolonged period may contain $7-10 \%$ of dissolved gas depending on its type, which practically does not affect the compressibility of these fluids. However, the compressibility of the oil depends to a large degree on the content of undissolved gas in the form of air bubbles, foam, etc. Oil flexibility is characterised by the so-called fluid bulk modulus $B_{\mathrm{f}}\left(\mathrm{N} / \mathrm{m}^{2}\right)$. In practice, hydraulic oil is a mixture of the fluid and a small amount of gas; thus, according to [30], the bulk modulus of the mixture may be calculated by considering a superposition of fluid deformations and undissolved gas, namely:

$$
\mathrm{B}_{\mathrm{f}, \mathrm{a}}=\frac{\mathrm{B}_{\mathrm{f}} \Delta \mathrm{p}_{\mathrm{i}}}{\Delta \mathrm{p}+\varepsilon \Delta \mathrm{p}_{\mathrm{i}}}
$$

where

$\varepsilon=\frac{V_{a}}{V_{f, a}}$ is the gas volume to gas-liquid mixture volume ratio under $\Delta p_{i}$ pressure, where this value was determined.

Example test results in this regard are presented in the form of graphs [30] (Figure 10). 


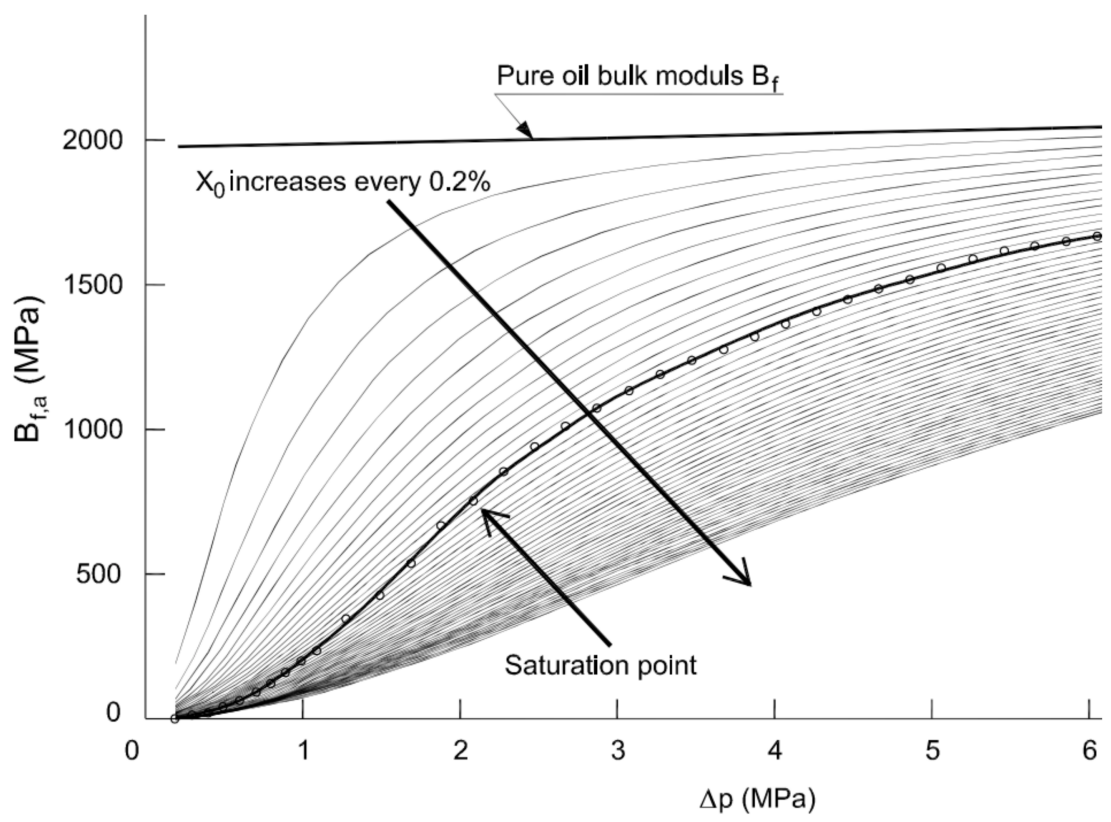

Figure 10. Comparison of the experimental results with a series of "compression-only" bulk modulus curves for an isothermal process [30].

Moreover, it should be emphasised that the fluid bulk modulus $\mathrm{B}_{\mathrm{f}}$ significantly depends on pressure and temperature (Figure 11).

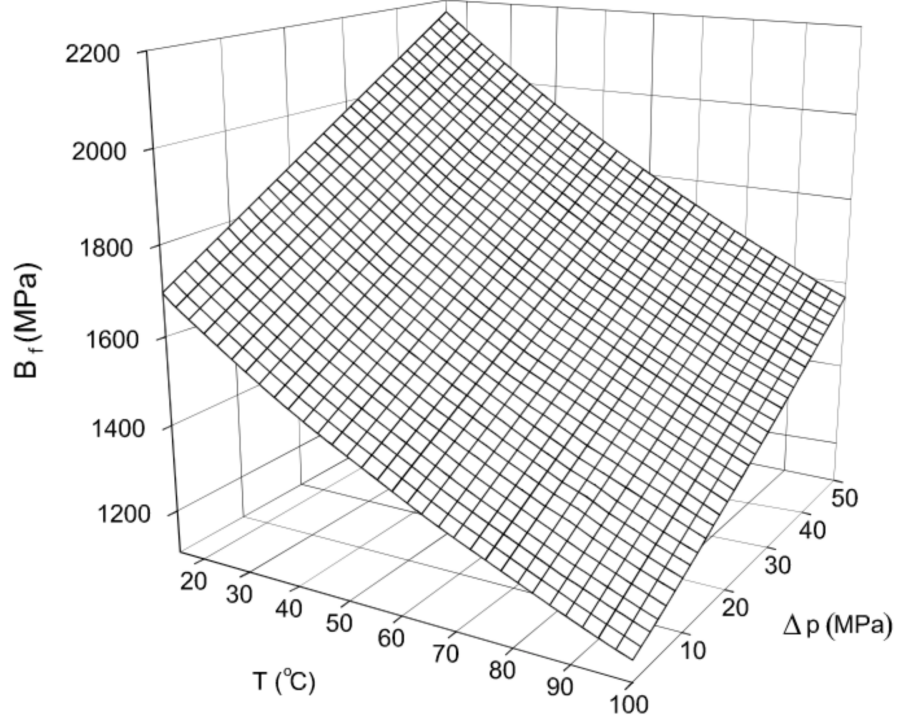

Figure 11. Isothermal bulk modulus of mineral oil in the initial drive phase; for low pressures, substantial changes in the fluid bulk modulus value might occur.

A comparison of different fluid models showed that the Nykanen model [30-33] is a suitable model for the authors' analyses, considering undissolved gas:

$$
\mathrm{B}_{\mathrm{f}, \mathrm{a}}=\frac{\left(\left(\frac{\mathrm{p}_{0}}{\mathrm{p}_{\mathrm{i}}}\right)^{\frac{1}{n}} \varepsilon+1-\varepsilon\right)^{2}}{\frac{\varepsilon}{n \mathrm{p}_{\mathrm{i}}}\left(\frac{\mathrm{p}_{0}}{\Delta \mathrm{p}_{\mathrm{i}}}\right)^{\frac{1}{n}}+\frac{1-\varepsilon}{\mathrm{B}_{\mathrm{f}}}},
$$


Estimating the air volume fraction is important. The method for the effective bulk modulus is proposed in [33]. Aeration of oil rapidly reduces the bulk modulus.

Air contamination strongly decreases the efficiency of fluid power systems and when the allowable limits are exceeded, the performance of the system deteriorates. The study [34] examined the air release process due to the flow in the system. The results show that relative air release decreases with an increase in air load and oil flow rate. Additionally, the design of the internal tank strongly influences the air release process.

\section{Modelling and Validation of Effective Torsional Stiffness for the Hydraulic Steering System}

During the operation of machines with articulated frame steering, as a result of the effect of the steering torque $\Delta \mathrm{M}_{\mathrm{s}}$ generated by external loads affecting a machine traveling straight ahead, there is a displacement of both pistons in hydraulic cylinders of the steering mechanism by a value of displacement $\Delta \mathrm{s}_{\mathrm{i}}$ in the inner cylinder and by a value of $\Delta \mathrm{s}_{\mathrm{o}}$ in the outer cylinder (Figure 12).

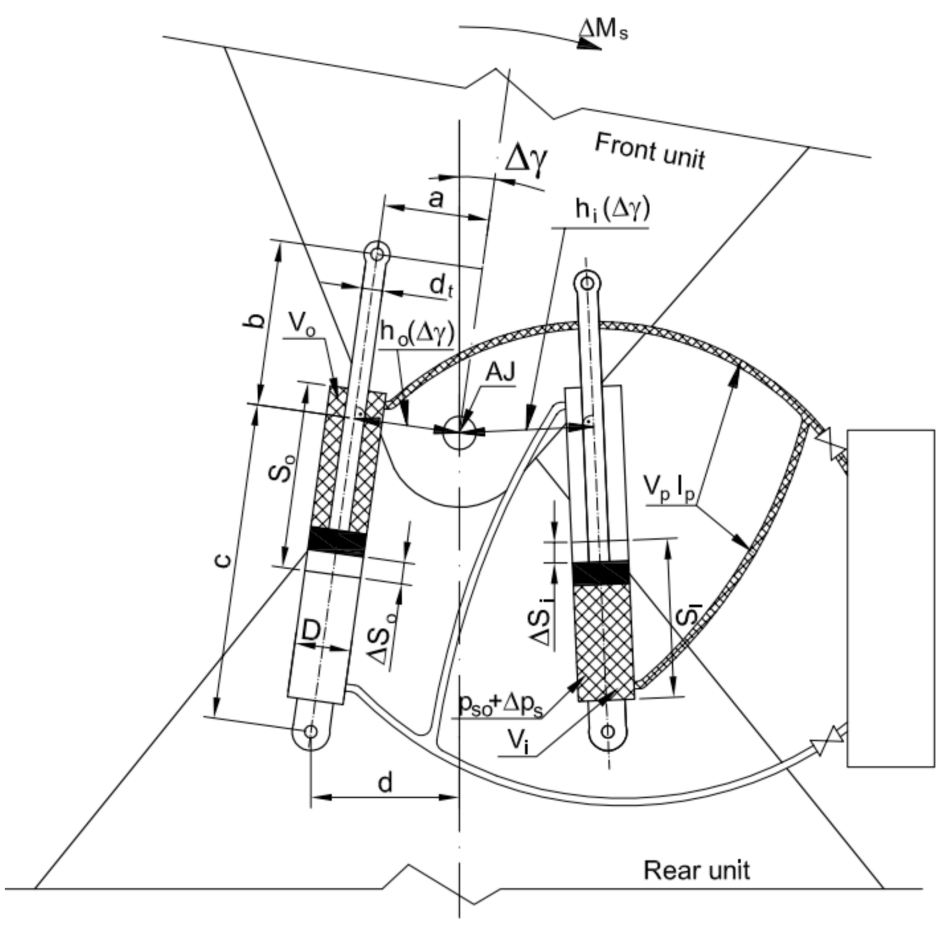

Figure 12. Schematic diagram of the AFSV units (frames) coupled using the hydraulic steering cylinders.

The front member (frame) and rear member (frame) should be precisely held relative to each other, ensuring the vehicle's travel is consistent with the driver's intent. Unfortunately, because of the steering system's flexibility, the vehicle members oscillate in the steering articulation joint $\mathrm{AJ}$ by an angle of $\pm \Delta \gamma$ relative to each other.

The effective (equivalent) torsional stiffness of the steering system may be defined as

$$
\mathrm{k}_{\mathrm{s}}=\frac{\partial \mathrm{M}_{\mathrm{s}}}{\partial \gamma}
$$

while for small turn angles $\left(\gamma<5^{\circ}\right)$, a linear character of the stiffness may be assumed, namely,

$$
\overline{\mathrm{k}_{\mathrm{s}}}=\frac{\Delta \mathrm{M}_{\mathrm{s}}}{\Delta \gamma}
$$

In this motion phase of the machine, the hydraulic cylinders should be "stiff" and stabilise the machine's front. 
Under the influence of external steering torque $\Delta \mathrm{M}_{\mathrm{s}}$, an equivalent reaction torque is generated in the steering system, which, according to Figure 12, may be written as

$$
\Delta \mathrm{M}_{\mathrm{s}}-\eta \Delta \mathrm{p}_{\mathrm{s}} \frac{\pi\left(\mathrm{D}^{2}-\mathrm{d}_{\mathrm{t}}^{2}\right)}{4} \mathrm{~h}_{\mathrm{o}}(\mathrm{a}, \mathrm{b}, \mathrm{c}, \mathrm{d}, \Delta \gamma)-\Delta \mathrm{p}_{\mathrm{s}} \frac{\pi \mathrm{D}^{2}}{4} \mathrm{~h}_{\mathrm{i}}(\mathrm{a}, \mathrm{b}, \mathrm{c}, \mathrm{d}, \Delta \gamma)=0
$$

After a transformation, one obtains

$$
\Delta M_{s}=\eta \Delta p_{s} \frac{\pi\left(D^{2}-d_{t}^{2}\right)}{4}\left[h_{o}(a, b, c, d, \Delta \gamma)+\frac{D^{2}}{D^{2}-d_{t}^{2}} h_{i}(a, b, c, d, \Delta \gamma)\right]
$$

According to [1], one may write

$$
\mathrm{h}_{\mathrm{o}}(\gamma)=\frac{|\mathrm{c}[\mathrm{b} \sin (\Delta \gamma)-\mathrm{a} \cos (\Delta \gamma)]-\mathrm{d}[\mathrm{b} \cos (\Delta \gamma)+\mathrm{a} \sin (\Delta \gamma)]|}{\sqrt{[\mathrm{c} \sin (\Delta \gamma)-\mathrm{a} \cos (\Delta \gamma)+\mathrm{d}]^{2}+[\mathrm{a} \sin (\Delta \gamma)+\mathrm{b} \cos (\Delta \gamma)+\mathrm{c}]^{2}}},
$$

and

$$
\mathrm{h}_{\mathrm{i}}(\gamma)=\frac{|\mathrm{c}[\mathrm{b} \sin (\Delta \gamma)+\mathrm{a} \cos (\Delta \gamma)]+\mathrm{d}[\mathrm{b} \cos (\Delta \gamma)-\mathrm{a} \sin (\Delta \gamma)]|}{\sqrt{[\mathrm{d}-\mathrm{b} \sin (\Delta \gamma)-\mathrm{a} \cos (\Delta \gamma)]^{2}+[\mathrm{b} \cos (\Delta \gamma)-\mathrm{a} \sin (\Delta \gamma)+\mathrm{c}]^{2}}}
$$

Equation (9) may be written as

$$
\Delta \mathrm{M}_{\mathrm{s}}=\eta \Delta \mathrm{p}_{\mathrm{s}} \frac{\pi\left(\mathrm{D}^{2}-\mathrm{d}_{\mathrm{t}}^{2}\right)}{4} \mathrm{~h}_{\mathrm{e}}\left(\mathrm{a}, \mathrm{b}, \mathrm{c}, \mathrm{d}, \mathrm{D}, \mathrm{d}_{\mathrm{t}}, \Delta \gamma\right)
$$

and

$$
\Delta \mathrm{M}_{\mathrm{s}}=\eta \Delta \mathrm{F}_{\mathrm{c}, \mathrm{o}} \mathrm{h}_{\mathrm{e}}\left(\mathrm{a}, \mathrm{b}, \mathrm{c}, \mathrm{d}, \mathrm{D}, \mathrm{d}_{\mathrm{t}}, \Delta \gamma\right),
$$

where

$$
\Delta \mathrm{F}_{\mathrm{C}, \mathrm{o}}=\mathrm{k}_{\mathrm{o}} \Delta \mathrm{s}_{\mathrm{O}}
$$

The change in the $\Delta \mathrm{s}_{\mathrm{O}}$ value may be defined as

$$
\Delta \mathrm{s}_{\mathrm{o}}=\mathrm{h}_{\mathrm{o}}(\mathrm{a}, \mathrm{b}, \mathrm{c}, \mathrm{d}, \Delta \gamma) \tan (\Delta \gamma)
$$

Substituting Equations (14) and (15) into Equation (13), one obtains

$$
\Delta \mathrm{M}_{\mathrm{s}}=\eta \mathrm{k}_{\mathrm{o}} \mathrm{h}_{\mathrm{o}}(\mathrm{a}, \mathrm{b}, \mathrm{c}, \mathrm{d}, \Delta \gamma) \tan (\Delta \gamma) \mathrm{h}_{\mathrm{e}}\left(\mathrm{a}, \mathrm{b}, \mathrm{c}, \mathrm{d}, \mathrm{D}, \mathrm{d}_{\mathrm{t}}, \Delta \gamma\right)
$$

As already mentioned, the global linear stiffness $\mathrm{k}_{0}$ in a hydraulic cylinder mainly depends on the flexibility of hoses and the flexibility of the fluid, taking into account undissolved air. The actuator's body may be assumed to be stiff in this case.

The equivalent modulus $B_{\mathrm{e}}$ of elasticity of the hydraulic steering system of an articulated vehicle, taking into account the moduli of oil-gas mixture $B_{f, a}$ and flexible hydraulic hoses $\mathrm{B}_{\mathrm{p}, \mathrm{e}}$, may be expressed as the following dependence:

$$
\begin{gathered}
\frac{1}{\mathrm{~B}_{\mathrm{e}}}=\frac{1}{\mathrm{~B}_{\mathrm{f}, \mathrm{a}}}+\frac{1}{\mathrm{~B}_{\mathrm{p}, \mathrm{e}}} \cdot \frac{\mathrm{V}_{\mathrm{p}, \mathrm{s}}}{\mathrm{V}_{\mathrm{c}}}, \\
\mathrm{V}_{\mathrm{c}}=\mathrm{V}_{\mathrm{p}, \mathrm{s}}+\left(\mathrm{V}_{\mathrm{o}}+\mathrm{V}_{\mathrm{i}}\right)
\end{gathered}
$$

Because of a complex composite structure of flexible hydraulic hoses, it is best for practical purposes to determine the modulus $B_{p}$ experimentally (Figure 9). The bulk modulus of flexible hydraulic hoses of the test machine with a length of $1=0.64 \mathrm{~m}$, determined based on our experimental studies (Figure 9) is described by a regression model:

$$
\mathrm{B}_{\mathrm{p}}=-0.0389 \Delta \mathrm{p}_{\mathrm{s}}^{4}+2.0562 \Delta \mathrm{p}_{\mathrm{s}}^{3}-37.876 \Delta \mathrm{p}_{\mathrm{s}}^{2}+313.74 \Delta \mathrm{p}_{\mathrm{s}}
$$


Meanwhile, the effective bulk modulus of these flexible hydraulic hoses, considering their curvature radius and temperature of $60^{\circ} \mathrm{C}$, is described by the following equation (valid up to $16 \mathrm{MPa}$ ):

$$
\mathrm{B}_{\mathrm{p}, \mathrm{e}}=0.85 \mathrm{~B}_{\mathrm{p}}
$$

Multiplying Equation (15) by $\mathrm{V}_{\mathrm{c}}$, one obtains

$$
\mathrm{c}=\frac{\mathrm{V}_{\mathrm{c}}}{\mathrm{B}_{\mathrm{f}, \mathrm{a}}}+\frac{\mathrm{V}_{\mathrm{p}, \mathrm{s}}}{\mathrm{B}_{\mathrm{p}}}=\mathrm{c}_{\mathrm{f}, \mathrm{a}}+\mathrm{c}_{\mathrm{p}}
$$

Substituting Equation (16) into (19), one obtains

$$
\mathrm{c}=\frac{\mathrm{Vp}, \mathrm{s}+\mathrm{Vo}+\mathrm{Vi}}{\mathrm{B}_{\mathrm{f}, \mathrm{a}}}+\frac{\mathrm{V}_{\mathrm{p}, \mathrm{s}}}{\mathrm{B}_{\mathrm{p}}}
$$

Adopting a constant value of the hydraulic capacity of the system allows for the application of a mechanical analogy in the form of elastic bonds with a constant stiffness $\mathrm{k}$. The analogous stiffness of elastic bonds $\mathrm{k}$ of a mechanical system, which is responsible for the hydraulic capacity of the system, is defined, in a general sense, by the following dependency:

$$
\mathrm{k} \stackrel{\text { def }}{=} \frac{\mathrm{A}^{2}}{\mathrm{c}}
$$

According to Figure 7, in the case of a hydraulic steering system, the authors obtained a formula defining the global stiffness, reduced to the outer steering hydraulic cylinder, in the following form:

$$
\mathrm{k}_{\mathrm{o}}=\left[\frac{\pi\left(\mathrm{D}^{2}-\mathrm{d}_{\mathrm{t}}^{2}\right)}{4}\right]^{2} \frac{1}{\mathrm{c}}
$$

At this point, it should be mentioned that the surface area of the hydraulic cylinder's piston and the fluid column height in the cylinder affect the oil stiffness in the cylinder and, consequently, the effective stiffness of the steering system. The stiffness of oil $\mathrm{k}_{\mathrm{f}}$ is given by the following formula:

$$
\mathrm{k}_{\mathrm{f}}=\mathrm{B}_{\mathrm{f}} \mathrm{A} / \mathrm{h}_{\mathrm{f}}
$$

while the stiffness of air $\mathrm{k}_{\mathrm{air}}$ is given by the following formula:

$$
\mathrm{k}_{\text {air }}=\mathrm{B}_{\mathrm{air}} \mathrm{A} / \mathrm{h}_{\text {air }}
$$

\section{Validation of Mathematical Model for Effective Torsional Stiffness of the Hydraulic Steering System}

The mathematical model of the equivalent torsional stiffness $\mathrm{k}_{\mathrm{s}}$ of a hydraulic steering system, presented above, was validated experimentally on a test machine shown above with a steering hydraulic cylinders configuration (mode A), as shown in Figure 13. The experiment is performed for three steering system configurations geometrical parameters as shown in Figure 13 mode 1-3. Parameters a-d relates to the dimensions shown on Mode 3. 


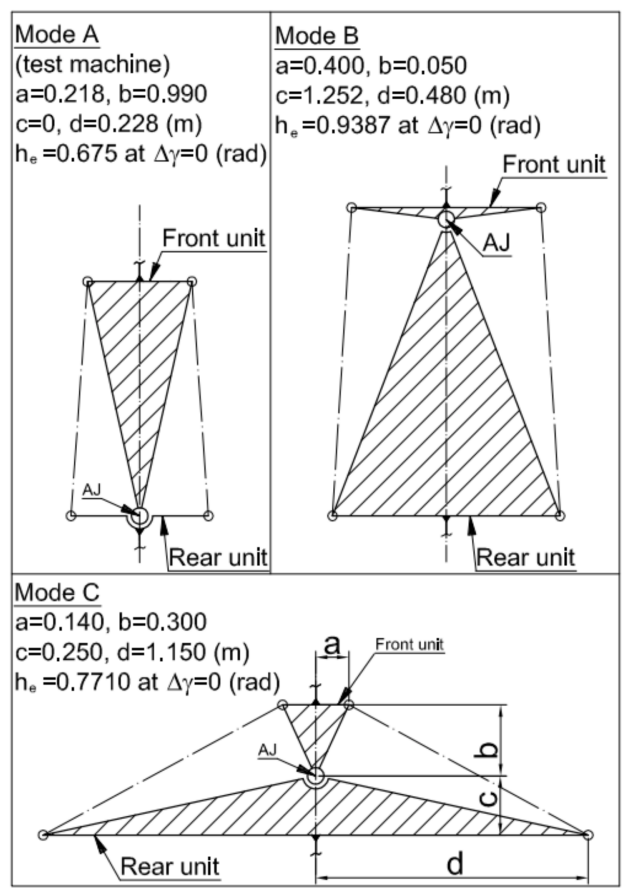

Figure 13. Configurations of the hydraulic steering geometry used in the simulation calculations.

Figure 14 presents the results of validation of the mathematical model of equivalent torsional stiffness $\mathrm{k}_{\mathrm{s}}$ of a hydraulic steering system carried out on a test machine.

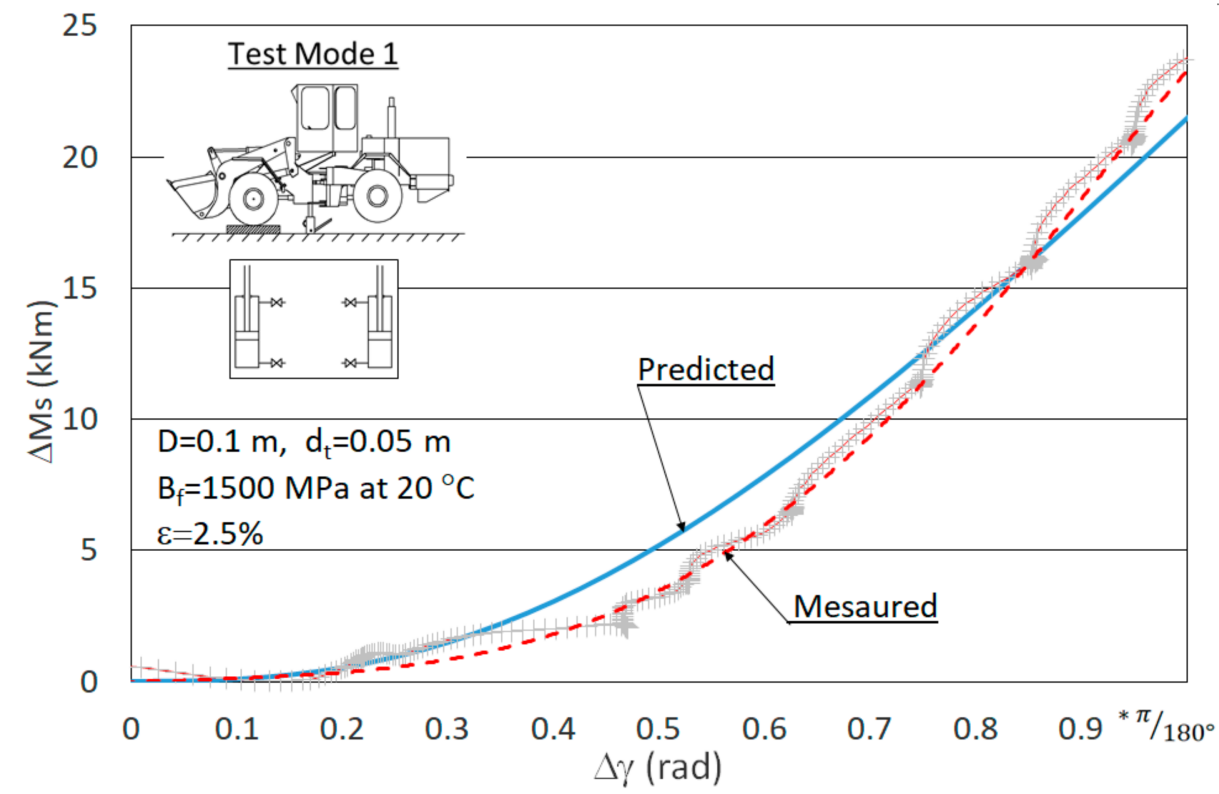

Figure 14. Validation of the mathematical model of the equivalent torsional stiffness $\mathrm{k}_{\mathrm{s}}$ of a hydraulic steering system on a test machine.

These results indicate a good, practically acceptable accordance of calculation results of the model with experimental results. Taking into account the positive results of the validation of the mathematical model, a series of variant calculations was carried out that considered significant parameters of the hydraulic steering mechanism. 


\section{Computational Results}

Based on this, the effective stiffness of the steering system of the test machine (mode A) was calculated with and without the flexible hydraulic hoses, as presented in Figures 15 and 16.

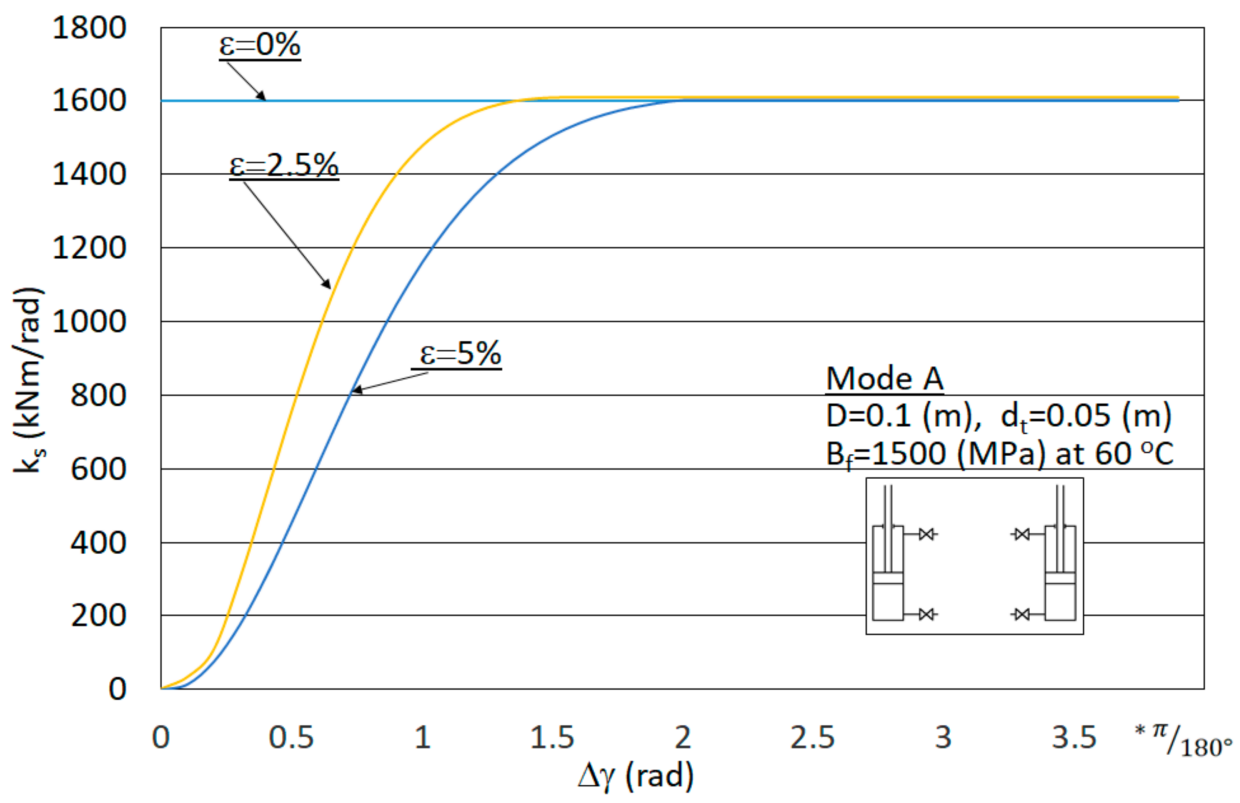

Figure 15. Results of calculations of the effective stiffness $k_{s}$ of the test machine's steering system (mode A) without the flexible hydraulic hoses.

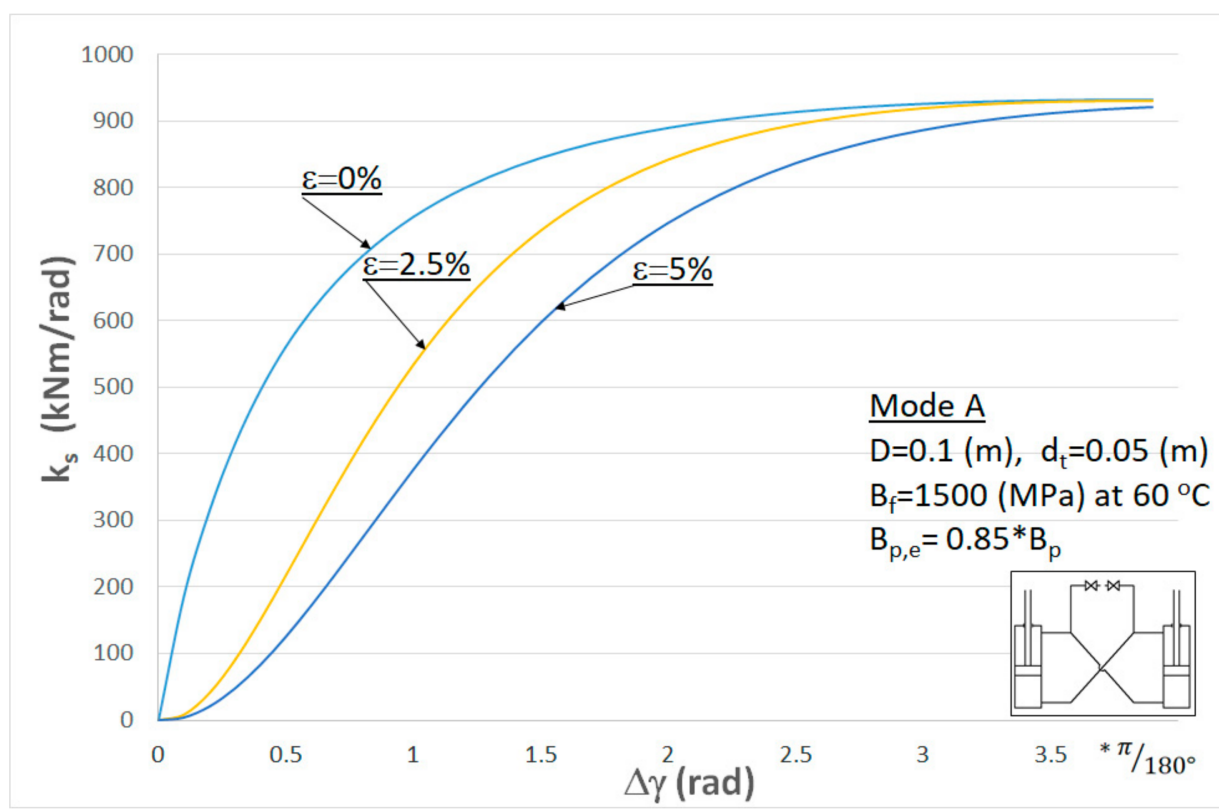

Figure 16. Results of calculations of the effective stiffness $\mathrm{k}_{\mathrm{s}}$ of the test machine's steering system (mode A) with the flexible hydraulic hoses.

The results of the calculations showed that the elastic hydraulic hoses significantly decreased the stiffness of the steering system by almost $50 \%$ for the given case.

The calculations based on the model, as presented above, confirmed that at a constant oil volume, a linear increase in effective torsional stiffness $k_{\mathrm{s}}$ with an increase in the surface area of the hydraulic cylinder (Figure 17). The calculations also showed that an increase in the capacitance $c$ of the hydraulic steering system and an increase in the undissolved 
air content cin the oil were accompanied by a significant decrease in effective torsional stiffness $\mathrm{k}_{\mathrm{s}}$ (Figure 18).

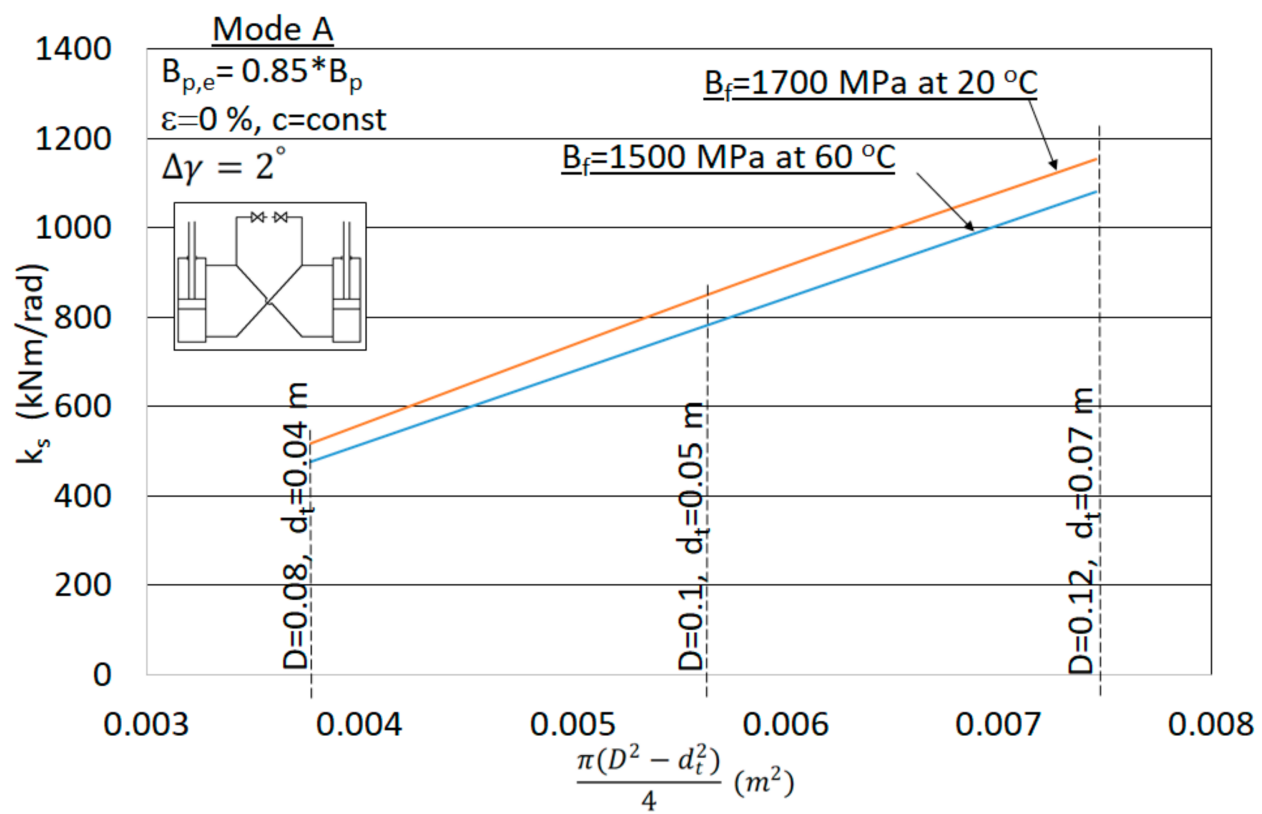

Figure 17. Influence of effective surface area of a hydraulic cylinder at a constant capacitance of the hydraulic system $\mathrm{c}=$ const, and bulk modulus of oil $\mathrm{B}_{\mathrm{f}}$ on equivalent torsional stiffness $\mathrm{k}_{\mathrm{s}}$ of the steering system.

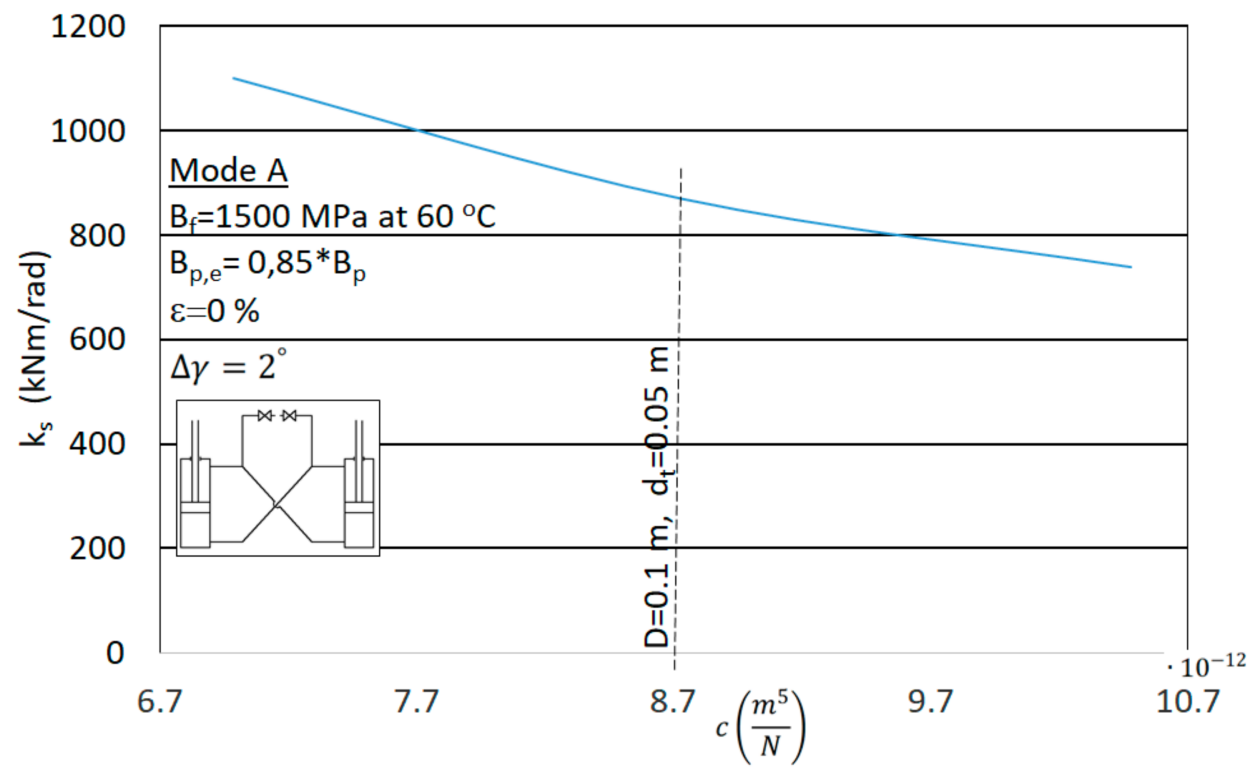

Figure 18. Influence of the capacitance of the hydraulic steering system on its equivalent torsional stiffness $\mathrm{k}_{\mathrm{s}}$.

Another very important factor that affects the equivalent stiffness of the steering system is the configuration of hydraulic cylinders, which is characterised by the parameters $\mathrm{a}, \mathrm{b}, \mathrm{c}$, and d, shown in Figure 19. As one can see from these calculations, the configuration of hydraulic cylinders had a significant influence on the so-called structural stiffness of the steering system as a component of the equivalent stiffness of this steering system. 


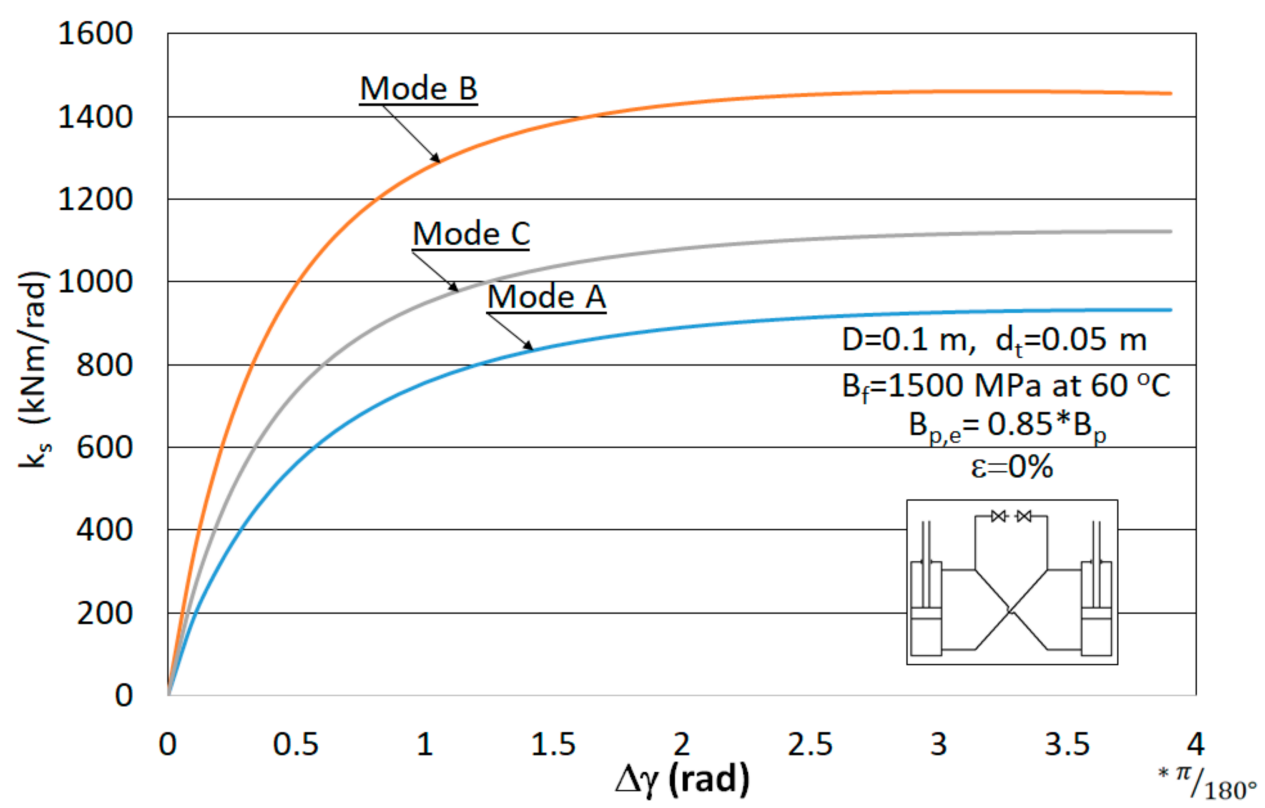

Figure 19. Influence of the configuration of hydraulic cylinders of the steering mechanism on its torsional stiffness $\mathrm{k}_{\mathrm{s}}$.

\section{Conclusions}

Based on the experimental and simulation studies, it was shown that the stiffness of the steering system played a very significant role on the directional stability and energy demand of the steering system. Numerous driver path corrections lead to an increase in power demand. Low steering system stiffness required a high number of articulation angle corrections and huge energy losses could be observed. The most popular method for increasing hydraulic stiffness leads to an increase in the system pressure to minimise the effect of low fluid stiffness. This method needs energy to keep the system pressurised. In this study, more efficient solutions for the increase in stiffness were proposed.

A global, experimentally verified novel mathematical model of effective (equivalent) torsional stiffness of a hydrostatic steering system for AFSWVs with two hydraulic cylinders was developed and experimentally verified. Since this model took into account all the significant parameters, it enables engineers to optimally select, at the design stage, the parameters of the steering system that will ensure the required directional stability of an AFSWV, preventing snaking behaviour.

Simulation tests carried out using the proposed new model showed that the following factors significantly affected the effective stiffness of the steering system:

1. Flexible hydraulic hoses: their design solution, together with the material, their geometry, bend curvatures, internal pressure, and temperature of the oil, as well as their operating time. The flexibility of hydraulic hoses is described globally by the effective bulk modulus $B_{p, e}$. Because of the complex composite structure of flexible hydraulic hoses, for practical reasons, this modulus is best determined experimentally for the hoses used in a given case.

2. Effective bulk modulus of the working fluid vs. content of undissolved air, fluid temperature, and pressure. Many researchers assume this modulus as constant, which generates errors. The presented test results showed that undissolved air content in the fluid significantly decreased the effective modulus of bulk elasticity of the fluid, leading to a decrease in the effective stiffness of the steering system. For example, simulation tests for the test machine indicated that the flexibility of hydraulic hoses, taking into account the flexibility of the fluid contained in them, can decrease the effective stiffness of the steering system as much as $50 \%$ under operating conditions. 
3. Reduced hydraulic capacity (capacitance) of the steering system. Its increase is accompanied by a decrease in the effective stiffness of the hydraulic steering system.

4. Placement geometry of the hydraulic steering cylinders (described by geometrical parameters $a, b, c$, and d), which is an indicator of the so-called structural stiffness. In the presented mathematical model, two hydraulic steering cylinders were replaced from the point of view of energy with one equivalent hydraulic cylinder. The simulation results confirmed that the larger the equivalent arm of the force generated in the equivalent steering cylinder, the higher the effective stiffness of the steering mechanism.

5. The effective surface area of an equivalent hydraulic cylinder: the larger the surface area at a constant capacitance of the steering system, the higher the effective stiffness of the steering mechanism.

Author Contributions: Conceptualisation, P.D. and A.S.; methodology, A.S.; software, A.S.; validation, P.D. and A.S.; formal analysis, P.D. and A.S.; investigation, A.S.; resources, A.S.; data curation, A.S.; writing-original draft preparation, P.D. and A.S.; writing-review and editing, A.S.; visualisation, A.S.; supervision, P.D.; project administration, P.D. and A.S.; funding acquisition, A.S. All authors have read and agreed to the published version of the manuscript.

Funding: This research received no external funding.

Institutional Review Board Statement: Not applicable.

Informed Consent Statement: Not applicable.

Data Availability Statement: Not applicable.

Conflicts of Interest: The authors declare no conflict of interest.

\section{Nomenclature}

A Cross-section of the cylinder $\left(\mathrm{m}^{2}\right)$

$\mathrm{a}, \mathrm{b}, \mathrm{c}, \mathrm{d} \quad$ Geometrical parameters connected with the layout of the hydraulic cylinders of the steering system $(\mathrm{m})$

$\mathrm{B}_{\text {air }} \quad$ Bulk modulus of air $(\mathrm{Pa})$

$\mathrm{B}_{\mathrm{e}} \quad$ Equivalent bulk modulus of the hydraulic fluid reduced to take account of entrapped air of hose elasticity and temperature $(\mathrm{Pa})$

$\mathrm{B}_{\mathrm{f}} \quad$ Bulk modulus of the (deaerated) oil ( $\left.\mathrm{Pa}\right)$

$\mathrm{B}_{\mathrm{f}, \mathrm{a}} \quad$ Bulk modulus of the fluid as a mixture of the fluid and undissolved gas (Pa)

$\mathrm{B}_{\mathrm{p}}$ or $\overline{\mathrm{B}_{\mathrm{p}}} \quad$ Tangent or secant bulk modulus of hose $(\mathrm{Pa})$

$\mathrm{B}_{\mathrm{p}, \mathrm{e}} \quad$ Effective bulk modulus of flexible hydraulic hoses reduced to take account of temperature $(\mathrm{Pa})$

c Reduced hydraulic capacity (capacitance) of the system $\left(\mathrm{m}^{5} / \mathrm{N}\right)$

$\mathrm{c}_{\mathrm{f}, \mathrm{a}} \quad$ Capacitance of the oil-gas mixture $\left(\mathrm{m}^{5} / \mathrm{N}\right)$

$c_{p} \quad$ Capacitance of flexible hydraulic hoses $\left(\mathrm{m}^{5} / \mathrm{N}\right)$

$\mathrm{c}_{\mathrm{z}, \mathrm{i}} \quad$ Normal tyre damping (Ns/m)

$\mathrm{c}_{\mathrm{y}, \mathrm{i}} \quad$ Lateral tyre damping $(\mathrm{Ns} / \mathrm{m})$

$\mathrm{D}, \mathrm{d}_{\mathrm{t}} \quad$ Piston and piston rod diameter in hydraulic cylinders of the steering mechanism (m)

$\Delta \mathrm{F}_{\mathbf{c}, \mathbf{o}} \quad$ The resulting force of the effect of $\Delta \mathrm{M}_{\mathrm{S}}(\mathrm{N})$

$\mathrm{h}_{\text {air }} \quad$ Height of the cylinder chamber filled with air $(\mathrm{m})$

$h_{e} \quad$ Equivalent arm of vicarious hydraulic cylinder that is energetically equivalent to two hydraulic cylinders of steering mechanism (m)

$\mathrm{h}_{\mathrm{f}} \quad$ Height of the cylinder chamber filled with oil $(\mathrm{m})$

$h_{0}, h_{i} \quad$ Moment arm in the outer and inner hydraulic cylinders of the steering mechanism in relation to the steering joint $\mathrm{AJ}(\mathrm{m})$

$k_{o} \quad$ Global linear stiffness reduced to outer steering hydraulic cylinder, resulting mainly from the flexibility of liquid, taking into account the undissolved air and the flexibility of hydraulic hoses $(\mathrm{N} / \mathrm{m})$ 


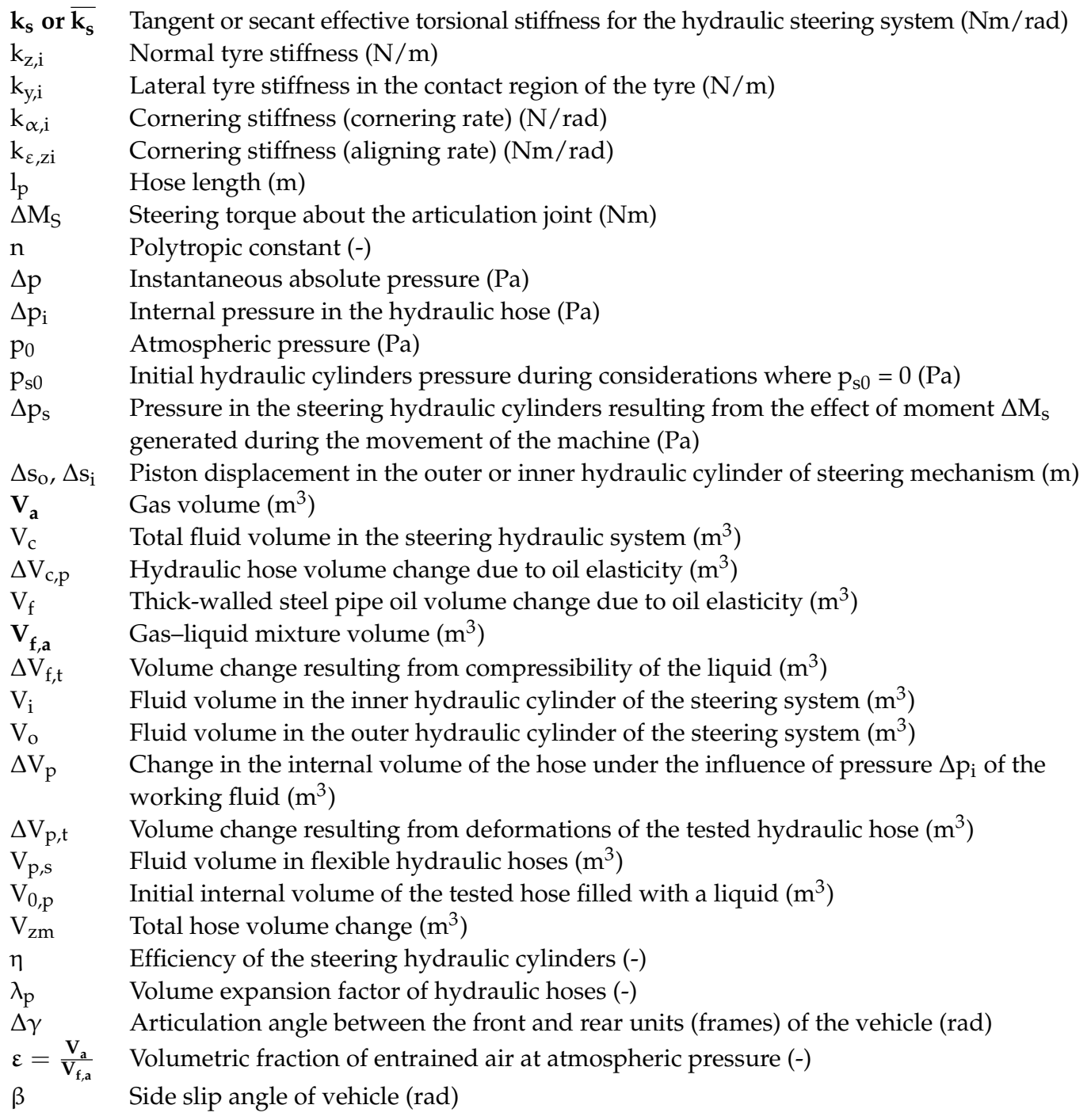

\section{References}

1. Dudziński, P. Lenksysteme für Nutzfahrzeuge; Springer: Berlin/Heidelberg, Germany; New York, NY, USA, 2005.

2. Łopatka, M.; Muszyński, T. Identification of Snaking Phenomenon of Articulated Wheeled Machines. WAT Bull. $2003,52,67-79$. Available online: http:/ /yadda.icm.edu.pl/baztech/element/bwmeta1.element.baztech-article-BWA2-0006-0152 (accessed on 30 October 2021). (In Polish)

3. ISO 5010:2019; Earth-Moving Machinery, Wheeled Machines, Steering Requirements. ISO: Geneva, Switzerland, 2019. Available online: https: / / www.iso.org/standard / 68453.html (accessed on 30 October 2021).

4. EN 12643:2014; Earth-Moving Machinery. Rubber-Tyred Machines. Steering Requirements. ISO: Geneva, Switzerland, 2014. Available online: https://standards.iteh.ai/catalog/standards/cen/1640d61b-5231-43e6-b9ba-a72111d79a1b/en-12643-2014 (accessed on 30 October 2021).

5. SAE J1511/ISO 5010-1994-02; Steering for Off-Road, Rubber-Tired Machines. SAE International: Wallendale, PA, USA, 1994. Available online: https:/ /www.sae.org/standards/content/j1511_199402 (accessed on 30 October 2021).

6. SAE J1790-1998-06; Self-Propelled Sweepers and Scrubbers Steering Requirements Single-Circuit Hydraulic Servo-Assisted Systems. SAE International: Wallendale, PA, USA, 1998. Available online: https://www.sae.org/standards/content/j1790_2003 $05 /$ (accessed on 30 October 2021).

7. Mitschke, M.; Wallentowitz, H. Dynamik der Kraftfahrzeuge; Springer: Berlin/Heidelberg, Germany; New York, NY, USA, 2004.

8. Rill, G. Road Vehicle Dynamics: Fundamentals and Modelling; CRC Press Taylor \& Francis Group: Boca Raton, FL, USA, 2020. Available online: https://www.taylorfrancis.com/books/mono/10.1201/9780429244476/road-vehicle-dynamics-georg-rill-abelarrieta-castro (accessed on 30 October 2021)

9. Dudziński, P.; Skurjat, A. Directional dynamics problems of an articulated frame steer wheeled vehicles. J. Kones Powertrain Transp. 2012, 19, 89-98. [CrossRef]

10. Dudziński, P.; Skurjat, A. Motion stability problems in an articulated frame steering wheeled vehicle, ATZ. Automob. Z. 2010, 4, 64-68. 
11. Dudziński, P.; Skurjat, A. Innovative steering system for optimizing operation properties in mobile working machines. In Proceedings of the Antriebstechnische Kolloquium (ATK), Aachen, Germany, 3-4 March 2015.

12. Technical Materials from Danfoss. Available online: https://www.danfoss.com/en/products/dps/valves-and-actuators/valves/ pvg-proportional-valves / (accessed on 30 October 2021).

13. Dudziński, P.; Hapel, G.; Skurjat, A. Method and Device for Automatic Adaptive Vehicle Control. Patent No. 216468, 21 August 2009. (In Polish)

14. Jiang, W.; Luo, X.; Chen, X. Influence of structural flexibility on the nonlinear stiffness of hydraulic system. Adv. Mech. Eng. 2016, 8, 1687814016663806. [CrossRef]

15. Feng, H.; Du, Q.; Huang, Y.; Chi, Y. Modelling study on stiffness characteristics of hydraulic cylinder under multi-factors. J. Mech. Eng. 2017, 63, 447-456. [CrossRef]

16. Zhu, J.; Wang, Y.; Jiang, J.; Sun, B.; Cao, H. Unidirectional variable stiffness hydraulic actuator for load-carrying knee exoskeleton. Int. J. Adv. Robot. Syst. 2017, 14, 1729881416686955. [CrossRef]

17. Horton, D.N.L.; Crolla, D.A. Theoretical Analysis of the Steering Behaviour of Articulated Frame Steer Vehicles. Veh. Syst. Dyn. 1986, 15, 211-234. [CrossRef]

18. Azad, N.L.; McPhee, J.; Khajepour, A. The effects of front and rear tires characteristics on the snaking behaviour of articulated steer vehicles. In Proceedings of the 2005 IEEE Vehicle Power and Propulsion Conference, Chicago, IL, USA, 7 September 2005; Volume 7-9.

19. He, Y.; Khajepour, A.; McPhee, J.; Wang, X. Dynamic modelling and stability analysis of articulated frame steer vehicles. Int. J. Veh. Syst. 2005, 12, 28-59. [CrossRef]

20. Azad, N.L.; McPhee, J.; Khajepour, A. Off-road lateral stability analysis of an articulated steer vehicle with a rear-mounted load. Int. J. Veh. Syst. Model. Test. 2005, 1, 106-130. [CrossRef]

21. Rehnberg, A.; Drugge, L.; Trigell, A.S. Snaking stability of articulated frame steer vehicles with axle. Int. J. Heavy Veh. Syst. 2010, 17, 119-138. [CrossRef]

22. Rehnberg, A. Suspension Design for Off-Road Construction Machines. Ph.D. Thesis, KTH, School of Engineering Sciences (SCI), Stockholm, Sweden, 2011.

23. Dudziński, P.; Skurjat, A. Directional stability control of body steer wheeled articulated vehicles. In Dynamical Systems Theory and Applications; Springer: Łódź, Poland, 2018.

24. Skurjat, A. Tests of influence of geometry and elasticity of hoses of hydraulic articulated steering system on its stiffness. In Proceedings of the 24th International Conference Engineering Mechanics, Svratka, Czech Republic, 14-17 May 2018.

25. Muszyński, M. Snaking of Articulated Wheeled Vehicles with a Hydrostatic Steering System. Ph.D. Thesis, WAT, Warsaw, Poland, 2004. (In Polish)

26. Perez, J.A.L.; De Pieri, E.R.; De Negri, V.J. Force control of hydraulic actuators using additional hydraulic compliance J. Mech. Eng. 2018, 64, 579-589.

27. Brunner, H. Untersuchungen zum elastischen Verhalten von Hydraulikschläuchen bei Druckbeaschlagung. Maschinenbautechnik $1975,24,549-552$.

28. Guillon, M. Etude et Determination des Systemes Hydrauliques; Dunod: Paris, France, 1961.

29. Fiebig, W.; Spławski, M. Influence of Structure and Static Pressure on Transmission of Vibrations in Flexible Hydraulic Hose. In Proceedings of the Conference Hydraulic Drives in Machines and Vehicles; Wrocław University of Science and Technology: Wrocław, Poland, 2012; pp. 35-42. (In Polish)

30. Gholizadeh, H. Modeling and Experimental Evaluation of the Effective Bulk Modulus for a Mixture of Hydraulic Oil and Air. Ph.D Thesis, Philosophy in the Department of Mechanical Engineering, University of Saskatchewan, Saskatoon, SK, Canada, 2013.

31. Knezevic, D.; Milasinovic, A.; Milavanovic, Z.; Savic, V. Analysis of changes of bulk modulus of mineral oil-Effects on the dynamic behaviour of hydraulic actuators. In Proceedings of the 12th International Conference on Tribology, Kragujevac, Serbia, 11-13 May 2011.

32. Stojanoski, G.; Rath, G.; Gimpel, M. The effects of bulk modulus on the dynamics of controlled independent metering system. In Proceedings of the Sixteenth Scandinavian International Conference on Fluid Power, Tampere, Finland, $22-24$ May 2019.

33. Sakama, S.; Kitazawa, Y.; Sugawara, Y.; Tanaka, Y. Estimating the air volume fraction in hydraulic oil by measuring the effective bulk modulus. In Proceedings of the 11th International Fluid Power Conference, Aachen, Germany, 19-21 March 2018.

34. Longhitano, M.; Protase, A.; Murrenhoff, H. Experimental investigation of the air release in hydraulic reservoirs. In Proceedings of the 10th International Fluid Power Conference, Dresden, Germany, 8-10 March 2016. 